IZA DP No. 5659

School Access, Resources, and Learning Outcomes: Evidence from a Non-formal School Program in Bangladesh

Hai-Anh Dang

Leopold Sarr

Niaz Asadullah

April 2011 


\title{
School Access, Resources, and Learning Outcomes: Evidence from a Non-formal School Program in Bangladesh
}

\author{
Hai-Anh Dang \\ World Bank
}

Leopold Sarr

World Bank

Niaz Asadullah

University of Reading

and IZA

\section{Discussion Paper No. 5659 \\ April 2011}

IZA

P.O. Box 7240

53072 Bonn

Germany

Phone: +49-228-3894-0

Fax: +49-228-3894-180

E-mail: iza@iza.org

Any opinions expressed here are those of the author(s) and not those of IZA. Research published in this series may include views on policy, but the institute itself takes no institutional policy positions.

The Institute for the Study of Labor (IZA) in Bonn is a local and virtual international research center and a place of communication between science, politics and business. IZA is an independent nonprofit organization supported by Deutsche Post Foundation. The center is associated with the University of Bonn and offers a stimulating research environment through its international network, workshops and conferences, data service, project support, research visits and doctoral program. IZA engages in (i) original and internationally competitive research in all fields of labor economics, (ii) development of policy concepts, and (iii) dissemination of research results and concepts to the interested public.

IZA Discussion Papers often represent preliminary work and are circulated to encourage discussion. Citation of such a paper should account for its provisional character. A revised version may be available directly from the author. 
IZA Discussion Paper No. 5659

April 2011

\section{ABSTRACT \\ School Access, Resources, and Learning Outcomes: Evidence from a Non-formal School Program in Bangladesh ${ }^{*}$}

This study reports evidence from an unusual policy intervention - The Reaching Out of School Children (ROSC) project - in Bangladesh where school grants and education allowances are offered to attract hard-to-reach children to schools comprised of a single teacher and a classroom. The operating unit cost of these schools is a fraction of that of formal primary schools. We use panel data to investigate whether ROSC schools are effective in raising enrolment and learning outcomes. Our findings suggest that there is a modest impact on school participation: ROSC schools increase enrolment probability between 9 and 18\% for children in the two age cohorts 6-8 and 6-10. They perform as well as non-ROSC schools in terms of raising test scores, and even have positive impacts on academically stronger students. There is also strong evidence of positive externalities on non-ROSC schools in program areas. These results point to the effectiveness of a new model of non-formal primary schools that can be replicated in similar settings.

JEL Classification: $\quad 121,010$

Keywords: non-formal school, impact evaluation, multiple treatments, learning outcomes

Corresponding author:

Hai-Anh Dang

South Asia Human Development Sector

World Bank

1818 H Street NW, MC3-311

Washington, DC 20433

USA

E-mail: hdang@worldbank.org

\footnotetext{
* We thank Amit Dar, Celine Ferre, Deon Filmer, Dilip Parajuli, Christel Vermeersch, Liang Choon Wang, and participants at a seminar at the World Bank for comments on previous versions of this paper. The findings and interpretations in this paper do not necessarily reflect the views of the World Bank or its Executive Directors.
} 


\section{Introduction}

Despite their seemingly indispensable roles in promoting student educational outcomes, there have been mixed results on the impacts of school supply and resources on access and learning outcomes (Hanushek, 2006). Findings from recent rigorous impact evaluation studies suggest that this is particularly the case for developing countries. On one hand, providing educational inputs such as textbooks (Glewwe, Kremer and Moulin, 2009), flip charts (Glewwe et al., 2004), and reduced teacher-pupil ratios (Duflo, Dupas, and Kremer, 2010) were generally found to have either no or very limited impacts on student test scores. On the other hand, other inputs such as remedial education programs (Banerjee et al., 2007), extra after-school classes (Banerjee et al., 2010), free school uniform (Evans, Kremer, and Ngatia, 2008), and reduced student fees and scholarship (Kremer, Miguel, and Thorton, 2009) were found to increase student reading skills and test scores and/ or decrease drop-out rates. Even the building of new schools does not always lead to large gains in school enrolment rates (Filmer, 2007). It appears that no consensus has been reached on the best school (policy) interventions to expand educational opportunities in developing countries. ${ }^{1}$

Even in the case such a consensus exists, providing more inputs into the existing systems may not bring the best outcomes. Institutional issues with educational systems in developing countries such as corruption, lack of transparency, and inefficient use of resources may severely impair the effectiveness of increased school resources (Glewwe and Kremer, 2006). In response to these problems, an alternative schooling model has

\footnotetext{
${ }^{1}$ There is conflicting evidence as well about other school supply interventions such as teacher performance pay, which is found to have positive impacts on test scores in India (Muralidharan and Sundararaman, 2009) but no or limited impacts in Kenya (Glewwe, Ilias, and Kremer, 2010). See also Glewwe and Kremer (2006) and Kremer and Holla (2009) for more general review of the literature on the impacts of school inputs, and Dang and Rogers (2008) for a review on the impacts of extra tutoring classes.
} 
been introduced: the non-formal schooling system. Starting in the late 1970s with the Escuela Nueva (New School) program in rural Colombia (Psacharopolous, Rojas, and Velez, 1993; McEwan, 1998), the non-formal schooling movement is gaining more popularity and has spread to many developing countries including the BRAC (Bangladesh Rural Advancement Committee) primary school program in Bangladesh in the mid-1980s (Chabbot, 2006), the Community School program in Egypt in the early 1990s (Farrell, 2004), and the School for Life program in Ghana in the late 1990s (Hartwell, 2006).

In spite of their different names, these programs appear to share at least three common characteristics: they are usually operated by non-state providers (in particular, NGOs) with strong community participation, they have low operational costs, and they cater to vulnerable and hard-to-reach students who were excluded for various reasons from the formal education system. ${ }^{2}$ It is notable that these programs are currently spreading to urban areas, post-primary schooling levels, and formal public schools as well. The Reaching Out-Of-School Children (ROSC) program we evaluate in this paper is a particular example where, inspired by the 'success' of the BRAC model, ${ }^{3}$ the Government of Bangladesh brought this model into the formal schooling system and expanded it on a large scale. Since 2005, ROSC has provided more than 15,000 schools (learning centers) serving over 500,000 educationally disadvantaged children in the poorest 60 Upazilas

\footnotetext{
${ }^{2}$ See Farrell and Hartwell (2008) and Ahmed (2008) for two recent (and qualitative) reviews of non-formal school programs.

${ }^{3}$ A BRAC school is a school consisting of one teacher and one classroom that caters to out-of-school (and usually marginalized) children which is operated by the NGO BRAC. Although BRAC schools and government public schools teach the same the same competency-based curriculum, Chabbott (2006) points out three key operational differences between these schools: i) student intake occurs every four years at the former but annually at the latter, ii) the average class size is 25 to 33 students at the former, but around twice higher at 61 students at the latter, and iii) while the former averages 4,091 contact hours per primary cycle, the corresponding figure at the latter is lower at 4,046. At the same time, BRAC schools have higher attendance rates (96 percent) and completion rates (94 percent) than government public schools (61 and 67 percent respectively), and BRAC students have higher test scores across several different subjects including life skills, reading, writing, and numeracy. Chabbott also estimates the cost per BRAC school completer is $\$ 84$, around one third that of $\$ 246$ for government public school.
} 
(sub-districts) in Bangladesh. The program is currently being expanded to include 30 additional Upazilas.

While these non-formal education programs have reached tens of thousands of schools and millions of students all over the world, there are very few studies that rigorously evaluate their impacts on enrolment and learning outcomes. Furthermore, the existing few studies provide mixed results. The most comprehensive assessment of the relative performance of BRAC schools in Bangladesh finds that non-formal schools in Bangladesh are effective in raising female enrolment and test scores in rural areas (Sukontamarn, 2006). In the absence of panel data, Sukontamarn relies on cross-sectional data and combines information on child year of birth and year of BRAC school establishment in the village to compare the impacts of BRAC schools on enrolment across the exposed and unexposed birth cohorts. For test scores, she estimates the cross-section relationship between student performance and different types of schools, assuming that school selection bias can be reduced by controlling for student, family, and village characteristics. However, alternative evidence based on performance of secondary school students does not support the view that BRAC graduates enjoy a learning advantage over their peers educated in other school types (Asadullah, Chaudhury and Dar, 2007).

There is equally a lack of consensus on the impacts of non-formal schools for other developing countries. For instance, Arif and Saqib (2003) find no gap between public and NGO schools in terms of test scores for grade 4 students enrolled in 50 public, private, and NGO schools located across six districts in Pakistan; but another study also analyzes data from Pakistan and arrives at the opposite conclusion that non-governmental organization schools are more effective than government or private schools (Khan and 
Kiefer, 2007). Similar to the previous studies on Bangladesh, both these studies use crosssectional data for analysis and may thus suffer in varying degrees from estimation issues with school selection bias. ${ }^{4}$ Thus it remains unclear if the true causal impacts of nonformal schools have been correctly identified. ${ }^{5}$

In this paper, we investigate the impacts of ROSC schools on both school enrolment and test scores using rich panel data from household and school surveys and censuses in Bangladesh. Our contributions are threefold. First, ROSC is a large scale program that serves the most educationally disadvantaged children in Bangladesh. Understanding the program impacts on educational outcomes would be important in itself for the Government of Bangladesh $(\mathrm{GoB})$ and international donors in the cause of raising school enrolment and learning quality. Faced with a variety of intervention options but perhaps scanty rigorous impact evaluation evidence at the same time, policy makers could always use new results from impact evaluation studies such as ours.

Second, to our knowledge, our study is the first to evaluate the impacts of a large-scale government-financed non-formal school program on school enrolment and test scores. We do not know of any previous rigorous evaluation of a non-formal program that is mainstreamed into the formal primary education system. Our findings have much

\footnotetext{
${ }^{4}$ Only the two studies by Asadullah, Chaudhury, and Dar (2007) and Khan and Kiefer (2007) address school endogeneity issues with instrumental variables. However, the findings in these two studies are limited by the nature of the cross-sectional data they use. The former combines fixed-effects specifications and intimate knowledge about school supply in Bangladesh to tease out selection bias into secondary school, but does not address previous selection bias into primary school. The instruments in the latter consist of number of siblings, parental education, and household wealth, and are not likely to satisfy the exclusion restrictions. For example, parental education can directly affect student test scores through parental help with homework and better genetic endowments for children (i.e. student innate ability). Similarly, the number of siblings and household wealth can affect test scores respectively through the well-known quantity-quality tradeoff regime (see, for example, Becker and Lewis, 1973) and availability of learning materials such as textbooks and computers which are conducive to better school performance.

${ }^{5}$ In this paper we focus on the impacts of non-formal schools on school enrolment and test scores. See, for example, Sud (2010) for the impacts of non-formal schools on transition into post-primary education (who also relies on a cross-section of households for analysis).
} 
relevance for other countries that plan to adopt and/ or expand this schooling model, especially given the rising popularity of non-formal schools and the fact that our study country is Bangladesh — which has one of the oldest and most widespread non-formal school programs in the developing world. In addition, this non-formal school program has even more policy relevance since it also includes a demand-side component that provides stipends to students conditional on their school enrolment and performance.

Finally, the rich individual-level panel data that we collected allows us to provide more rigorous estimates in at least two major aspects. Firstly, we use a child effects model, which is at a disaggregated and more refined level than the usual school- or village- effects model employed by most previous studies. Together with standard errors for estimation results being clustered at the child level, this would control for unobserved individual heterogeneity in identifying the causal impacts of ROSC schools. Secondly, we use a (multiple) treatment/control model to evaluate the ROSC schools' effects on both schooling quantity (i.e., enrolment) and quality (i.e., standardized test scores), which should represent a good picture of its impacts.

We find that ROSC schools increase enrolment probability by between 9 and 18 percent for children in the age cohorts 6- 8 and 6-10, and perform as well as non-ROSC schools in terms of raising test scores. In particular, academically stronger students attending ROSC schools improve their test scores by around 0.2- 0.4 standard deviations compared to their peers at other schools. There is also strong evidence that ROSC schools bring about positive externalities on non-ROSC schools in program areas.

This paper consists of seven sections. The context for the country and the program description is provided in Section II, and the data is described in Section III. The impacts 
of the ROSC project on education outcomes as measured by student enrolment and test scores are discussed in Section IV and other program effects are considered in Section V, with the empirical estimation frameworks being respectively detailed in each Section. The relative efficiency of ROSC schools versus non-ROSC schools is discussed in Section VI and Section VII concludes.

\section{Country Background and Program Description}

\section{II.1. Country Background}

Bangladesh has made significant progress in primary education over the past two decades. With nearly 18 million children enrolled in about 80,000 primary schools in the country, primary gross enrolment rate exceeds $90 \%$ and the net enrolment rate is close to 70\% (our calculations using the 2005 Bangladesh Household Income and Expenditures Survey). ${ }^{6}$ Gender parity in primary education has also been achieved. Despite this important progress, considerable challenges remain. There is limited access to schooling for the poorest and a significant number of school-aged children are still out of school. Moreover, the quality of schooling remains weak as reflected in the low levels of learning observed (Asadullah, Chaudhury, and Dar, 2007).

To address these critical issues of low quality of school and inequitable access while pursuing the 2015 Education For All (EFA) goals, the Government of Bangladesh decided, in 2004, to embark on an innovative experiment to reach out-of-school children. A new schooling model (ROSC) akin to non-formal schools of BRAC was developed to serve out-of-school children who reside in under-provided areas and belong mostly to

\footnotetext{
${ }^{6}$ Primary enrolment can be further broken down as follows: $76 \%$ in public government schools, $11 \%$ in government-subsidized private schools, $5 \%$ in private schools, and the remaining in NGO and Madrassa schools (our calculations using the 2005 Bangladesh Household Income and Expenditures Survey).
} 
poor households. These new schools were thus largely set up in areas with limited provision of formal schools and have minimum operational costs. ROSC is a unique and innovative model in that it combines both supply and demand side interventions targeted towards children aged 7-14 who were left out of the formal primary education system, especially those from disadvantaged areas and groups.

\section{II.2. Program Description}

Sixty Upazilas in Bangladesh were chosen for the ROSC project based on their net enrollment rate (NER), primary completion rate, gender parity in enrollment and poverty rate. The first selection criterion requires selected Upazilas to have a NER lower than 85 per cent. Once this screening criterion is satisfied, selected Upazilas must fulfill two out of three following selection criteria: (i) the gender gap in enrolment should be greater, at least, than 2 percentage points; (ii) the primary completion rate should not exceed 50 per cent; and (iii) the poverty rate should be above 30 per cent.

Two major program interventions were designed for these Upazilas: the first is a school-only grant (G intervention) that was implemented in 23 Upazilas and the other is a school grant plus an education allowance to students (GA intervention) implemented in the remaining 37 Upazilas. The school grant intervention-ranging between Taka 25,00031,000 per school for GA schools and 55,000- 65,000 for G schools ${ }^{7}$ - provides funding for the purpose of establishing a new school (hereafter referred to as ROSC schools), together with educational materials and supplies, training, teacher salary, sanitation and safe drinking water, and maintenance and repairs. On the other hand, the education

\footnotetext{
${ }^{7}$ The exchange rate is around Taka 69 for one US dollar during 2006- 2009 (World Bank, 2011).
} 
allowance provides a stipend ranging between Taka 800 and 970 annually for eligible (e.g., out-of-school) children to attend school. ${ }^{8}$

The ROSC project is implemented by a ROSC implementation unit at the Department of Primary Education, Ministry of Primary and Mass Education, which is responsible for the overall implementation, monitoring and reporting on the project. However, day-to-day management of ROSC schools_-including establishment of the school, hiring of teachers, education service providers and utilization of the grants-is highly decentralized with a number of actors involved in the implementation. ROSC schools are managed and run by a Center Management Committee (CMC) ${ }^{9}$. We provide in Appendix 1 a more detailed comparison of the main characteristics of ROSC schools versus BRAC and GP schools.

Over the past five years of project implementation, the ROSC project managed to enroll and provide education allowances to about half million out-of-school children from 60 Upazilas, as well as grants to about 15,000 ROSC schools established under a US\$ 60 million investment project. ROSC is also credited with an ingrown monitoring cell with good capacity to collect, analyze and report data. However, ROSC monitoring cell lacks the capacity to carry out a rigorous evaluation of the project impacts. This study intends to fill that analytical gap.

\footnotetext{
${ }^{8}$ In Upazilas which receive education allowances and grants (GA) (i) each child in grade I-III receives Taka 800 annually while each child of grade IV-V receive Taka 970 annually. To continue to receive the education allowance, a student must maintain minimum pass mark of 40 percent in the annual examination and record 80 percent attendance. An annual grant of Taka 25,000-31,000 is provided to the CMCs of ROSC schools as discretionary grant for teacher salaries, quality improvements and payment for service providers. For Grants only (G) Upazilas, each ROSC school receives an annual grant of Taka 55,00065,000 annually depending on enrollment size to be used for the same discretionary purposes. However, students do not receive any education allowances at the ROSC schools in G Upazilas.

9 A Center Management Committee is usually comprised of 11 members, which include five parents/guardians, a local education officer, a local administrative officer, an NGO representative, the head of the local government primary school, a person from the community, and the teacher of the ROSC school. This teacher also serves as the CMC secretary.
} 
Unlike regular government primary (GP) schools which generally have five classrooms or more, ROSC schools are organized around a single teacher in a single classroom. This suggests that the unit operating cost of ROSC schools is likely to be lower than that of GP schools. We will return to discuss the efficiency of ROSC schools in a later section. In the next section, we describe the data for analysis.

\section{Data Description}

\section{III.1. Baseline and Follow-up Surveys}

We designed and implemented surveys at the household, school, and village levels to measure the impacts of the ROSC program. Both the household and school surveys have panel data with baseline and follow-up components. For the baseline survey, 14 Upazilas (8 GA Upazilas and 6 G Upazilas) were randomly selected from out of the 60 ROSC Upazilas for the treatment, and 6 non-ROSC Upazilas that were considered to have similar program eligibility ratings to the ROSC Upazilas (based on the same selection criteria above) were selected to form a comparison group. ${ }^{10}$

From each of these 20 Upazilas, 3 unions were randomly selected leading to a sample of 60 unions, and one village was randomly selected in each union. Then a random sample of 25 households was selected from each village for a detailed household survey, making the total sample of interviewed households in the baseline 1,500. Out of these 1,500 households, 800 households were randomly selected for re-interview in the follow-up survey, ${ }^{11}$ and detailed data was collected about children's school enrolment and household

\footnotetext{
${ }^{10}$ These 6 control Upazilas were randomly selected from a list of 98 non-ROSC Project Upazilas which were considered to have similar eligibility ratings as the ROSC Upazilas. More details are provided in Ahmed (2006)

${ }^{11}$ The follow-up survey was implemented in 12 Upazilas and 36 unions out of the 20 Upazilas and 60 unions of the baseline survey. A simple random sampling technique was adopted to sample from the
} 
expenditures from these households. A short census was also administered to all the households in these sampled villages and provides data on the village infrastructure, cultivation land areas, living standards (as measured by recent consumption of fish or meat), and educational achievement.

Out of these 60 selected villages, the baseline school survey collected data on 8 ROSC schools on average per village and some other primary schools, including government primary schools (GPS) and NGO schools. ${ }^{12}$ To measure the quality of education in ROSC schools and other formal primary schools, the baseline school survey administered an achievement test to all students who were currently enrolled in Grade 2 in these schools. In total, 5,063 Grade 2 students were tested, with the majority of these students (53\%) enrolled in ROSC schools and the remaining students (46\%) mostly enrolled in public primary schools.

Of these children, 3,019 children were selected for re-interview in the follow-up survey. ${ }^{13}$ Compared to the baseline, a higher percentage of these children $(67 \%)$ were found to be enrolled in ROSC schools but the remaining children were mostly enrolled in public primary schools. We could test most children at school; for those who were absent

surveyed baseline Upazilas, resulting in 9 ROSC Upazilas (5 GA Upazilas and 4 G Upazilas) and 3 nonROSC Upazilas being covered in follow-up survey. All the 36 unions (e.g., 36 villages) in the baseline survey located in these 12 Upazilas were then resurveyed. Unions and villages were respectively the primary sampling units (PSU) for the schools and the households. The main reason for this reduction in sample size is due to shortage of funding.

${ }^{12}$ For villages with more than 8 ROSC schools, 8 ROSC schools were randomly selected. For villages with fewer than 8 ROSC schools, all the ROSC schools in the village were selected and some ROSC schools in adjacent villages within the same union were selected to obtain 8 ROSC schools (DATA, March 2010). More details on the baseline surveys are provided in Ahmed (2006). A total of 333 ROSC schools, 63 government primary schools (GPS), and 104 NGO schools in both ROSC and non-ROSC areas were surveyed in the baseline school survey.

${ }^{13}$ In fact, 3,885 children took the test in the follow-up survey, but out of these children, 866 were new students who were not tested in the baseline survey. Thus we dropped these new children from the sample for analysis. 
from school on the test day we visited and tested them at home. ${ }^{14}$ In addition to test scores, the school survey also collected data on school infrastructure such as the working condition of blackboards, and whether the school has a toilet, alphabetic and numeric charts, electricity, and water.

However, our data suffers from several limitations. First, data on student characteristics were not collected in the baseline school survey (except for student gender and grade) and were only collected in the follow-up school survey. Thus while we have panel data (i.e., two observations) on student test scores, we only have a cross section of data on student characteristics from the follow-up school survey. Second, there is no information available to link the households in the baseline household census with those in the follow-up household census. Third, while there is some overlapping between the household data and the school data for some students, the sample size is too small to allow meaningful analysis. Thus we use the household survey and school survey separately to investigate the impacts of ROSC schools on enrolment and learning achievement respectively.

\section{III.2. Timing of Baseline and Follow-up Surveys and Effective Sample Sizes}

It is important to note that the timing of the baseline survey has a major impact on the design of our evaluation study. The baseline survey was implemented from February to April 2006; however, by early 2006, most of the ROSC project villages already had a ROSC school. Furthermore, given that a large number of ROSC schools were already in operation in 2006, data collected in (or after) 2006 is likely to be "contaminated" and not likely represents a good baseline.

\footnotetext{
${ }^{14}$ Out of the 3,019 children with both baseline and follow-up test scores, 2,182 children took the test at school while 837 students took it at home. Out of these 837 students, around $21 \%$ are school drop-outs and $58 \%$ are enrolled in ROSC schools.
} 
In order to circumvent the problem, the household surveys asked retrospective questions on enrolment for the three years preceding the surveys and collected data on enrolment for the children in these households from 2004 up to 2009. Thus we use data from the household surveys to look at the changes in enrolment rates for children before and after the introduction of ROSC schools. In other words, since the ROSC project came into full operation during 2005 and 2006, enrolment in 2004 can be considered pre-ROSC enrolment, and enrolment after 2006 can be considered post-ROSC enrolment. After dropping all the missing observations, panel data on 955 children in the age range 6 to 14 in 2004 are available for analysis.

Since we cannot force children to randomly enroll in ROSC schools or non-ROSC schools, we can only measure the changes in test scores over time for children who were already enrolled in these schools. These changes would measure the impacts of ROSC schools versus non-ROSC schools on the relative gains in student test score performance, assuming student (ability as measured by) test scores are comparable in the baseline. We will return to discuss this assumption in more detail in the next section. After cleaning the data (such as dropping students with missing household and school characteristics or students with suspicious data on current grade level and some transfer students), we are left with a sample of 2,306 students with test scores in both the baseline and follow-up surveys that can be analyzed.

\section{III.3. Summary Statistics}

Summary statistics were provided in Table 1 and Table 2 respectively for the estimation samples of children age 6- 14 in the panel household surveys and children with test scores in both the baseline and follow-up surveys. Children in our estimation sample 
are equally likely to enroll in school in both G and GA areas compared to non-ROSC areas (Table 1). However, it is perhaps not surprising that children living in ROSC areas or studying at ROSC schools are at a disadvantage compared to their peers in non-ROSC areas (schools) as shown by statistical t-tests.

Children in ROSC areas are more likely to live in households that have less educated members and lower household consumption levels, and are more likely to live in villages with lower educational achievement. Compared to children from ROSC areas, while children in $G$ areas live in villages with more cultivable land areas and electrification, those in GA areas live in villages with less cultivable land.

While children at $\mathrm{G}$ schools have comparable baseline test scores to those at nonROSC schools, children studying in GA schools have much lower baseline test scores (Table 2). Compared to their peers at non-ROSC schools, children at ROSC schools are somewhat older, live in poorer households with less educated parents, ${ }^{15}$ and study in schools with poorer infrastructures. For example, only 15 percent of ROSC schools have a number chart, while the corresponding number for non-ROSC schools is more than three times higher at 54 percent, and blackboards at ROSC schools have lower quality than those in public schools. ${ }^{16}$

The distribution of standardized test scores for G, GA, and non-ROSC schools are shown for 2006 and 2009 in Figure $1 .^{17}$ Test scores for G schools have a very similar distribution to those for non-ROSC schools for both years, and appear to have the same

\footnotetext{
${ }^{15}$ Note that these differences alone appear to indicate the success for the ROSC project in attracting these educationally disadvantaged children to school.

${ }^{16}$ The blackboard variable has four values ranging from 1 to 4 which respectively indicate in this order four statuses: unusable, disrepair, good, and very good.

${ }^{17}$ Test scores in 2006 and 2009 are standardized based on the mean and standard deviation from the scores for non-ROSC schools in 2006.
} 
improvement as those for non-ROSC schools. On the other hand, most of the distribution of the test scores for GA schools shifted to the right from 2006 to 2009, indicating that test scores at GA schools significantly improved in this period.

\section{Impacts of ROSC Program}

\section{IV.1. Impacts of ROSC Program on School Enrolment}

\section{Empirical Model}

From the preceding discussion on the timing of the ROSC project, it is evident that children in our sample were subject to a multiple treatment design. Since the panel household data provide observations on children's enrolment status for each year from 2004 to 2008, we can consider enrolment rates in 2004 as pre-ROSC outcomes, and enrolment rates from 2006 onwards as post-ROSC outcomes. ${ }^{18}$ Since we have data on children enrolment for several years from 2006 onwards, each of these years would represent a year where children are "treated" to the ROSC school model.

While we also have data on children's enrolment status in 2009 , we prefer to restrict the data to 2008 only. The main reason is that the pre-treatment year is 2004 , thus by 2008, children in grade 1 in 2004 must be in grade 5 in 2008 already. Restricting the sample to the year 2008 thus helps avoid the downward bias to the program effects caused by some children who drop out of school immediately after finishing primary school; however, as a robustness check we will also consider the results when the estimation sample includes 2009.

\footnotetext{
${ }^{18}$ Strictly speaking, the ROSC project covered most but not all villages in 2006, but we can still include the year 2006 in the model since we look at the impacts for each separate year.
} 
Thus we can use the following multiple treatment model to estimate the impacts of the ROSC project on children's probability of school enrolment ${ }^{19}$

$$
E_{i v t}=\alpha+\sum_{k=1}^{K} \beta_{k} P_{k}+\sum_{t=1}^{T} \delta_{t} Y_{t}+\sum_{k=1 t=1}^{K} \sum_{k}^{T} \gamma_{k t} P_{k} * Y_{t}+\eta Z_{i v t}+\mu_{i}+\varepsilon_{i v t}
$$

where the variables are defined as follows

$\alpha:$ constant term

$E_{i v t}$ : enrolment status for child $\mathrm{i}$ in village $\mathrm{v}$ at time t. $E_{i v t}$ equals 1 if the child is enrolled and 0 otherwise.

$P_{k}$ : program area, with $\mathrm{k}=1,2 . P_{1}$ being the Grant $(\mathrm{G})$ areas and $P_{2}$ being the Grant+ Allowance (GA) areas. The reference category is the non-ROSC areas.

$Y_{t}$ : year dummy variable, with $\mathrm{t}=2006,2007,2008$. The reference category is the year 2004.

$Z_{i v t}$ : other control variables from the baseline and follow-up household surveys including individual, household, and village characteristics. ${ }^{20}$ Individual characteristics in equation (1) include student gender and age. Household characteristics include the years of schooling for the most educated household member, household size, and household living standards (as measured by log of monthly per capita expenditure). However, there is no expenditure data in 2006 thus we use the expenditure aggregates from 2009 instead. Village characteristics include the share of households with electricity in the village, the

\footnotetext{
${ }^{19}$ We can also compare enrolments between the baseline and follow-up surveys at the village level instead of the children level. However, it is not optimal to do so for at least two reasons. First, there is a limited number of observations at the village level (18 observations for a single year or 36 observations for 2006 and 2009), and second, much precision is lost when data at the household level have to be aggregated up to the village level. Thus we do not use the household census data for regression analysis. However, we did run some regressions using this data, and there are no statistically significant impacts for ROSC schools.

${ }^{20}$ There are only two observations (from two rounds of household surveys) on each of these variables. Thus we use the values in the 2006 survey for the years 2004 and 2006, and the values in the 2009 survey for the years 2007 and 2008 .
} 
average cultivable land area for households in the village, the share of cultivable land under irrigation in winter season, village living standards (as measured by the share of households in the village that consumed/ purchased fish or meat in the past 7 days), and village education levels (as measured by the share of villagers having passed Grade 5 or higher).

$\mu_{i}$ : child (individual) random effects, where $\mu_{i} \mid P_{k}, Y_{t}, Z_{i v t}$ is assumed to have a normal distribution with mean 0 and variance $\sigma_{\mu}^{2}$.

$\varepsilon_{i v t}:$ random error term. where $\varepsilon_{i v t} \mid P_{k}, Y_{t}, Z_{i v t}$ is assumed to have a normal distribution with mean 0 and variance $\sigma_{\varepsilon}^{2}$. A more interesting coefficient that will also be estimated is $\rho\left(=\frac{\sigma_{\mu}^{2}}{\sigma_{\mu}^{2}+\sigma_{\varepsilon}^{2}}\right)$, which measures the within-individual correlation. If $\rho$ is statistically significantly different from 0 , we need to use the random-effects model; otherwise, the random-effects component is not necessary. To address any possible heterogeneity in the error terms, we will use the robust standard errors clustered at the individual in our estimates.

We use a linear probability model with individual random effects to estimate equation (1). ${ }^{21}$ The most interesting coefficients in equation (1) are $\gamma_{k t}$, which are the coefficients on the multiple treatment variables $P_{k} * Y_{t}$ obtained by interacting the program variables and the year variables. These coefficients represent the treatment impacts on enrolment in

\footnotetext{
${ }^{21}$ Strictly speaking, the dependent variable is binary thus it may be more appropriate to use a random-effects probit. However, we prefer to use the random effects linear probability model since it will be easier to interpret results. In addition, it is also easier to control for robust standard error with this model. Another option is to use the child fixed-effects model, but Hausman test results (not shown) indicate no difference between this model and our random-effects model. In addition, we only have household consumption aggregrates for one year (2009), which will drop out in the fixed-effects model.
} 
each program area for each year after ROSC begins. In other words, these coefficients tell us about the impacts of ROSC on enrolment controlling for everything else.

To provide comparison and as a robustness check on the estimated results, we will use three sequential models: the first model includes only the program and year dummy variables and the treatment variables, the second model adds to the first model individual and household characteristics, and the third model adds to the second model village characteristics. If the sizes of the coefficients on the multiple treatment variables $P_{k} * Y_{t}$ remain similar across the different models, this would mean estimation results are robust and not explained away by, for example, the inclusion of household or village characteristics.

Since we analyze enrolment rates for the same age cohort over 5 years, 2004 to 2008, the age ranges we choose should be kept relevant to the primary school age. Thus we will consider three different age cohorts, which are the ages 6- 10, 6- 8, and 7- 14 in 2004. These three age cohorts will provide some comparison on the impacts of the projects, but these impacts can be different for each age cohort. Since these age cohorts are in 2004, by 2008-that is 4 years later-the age cohort 6- 8 would be 10- 12. This cohort went through primary school age during this interval, thus they were most likely to have been affected by the project.

Similarly, the age cohort 7- 14 in 2004 would be the age cohort 11- 18 in 2008, thus this age cohort would mostly have been past the primary school age by 2008 . Thus in terms of age, the age cohort 7- 14 in 2004 was likely to have been less affected by the project, except perhaps in the beginning post-ROSC years. The age cohort 6- 10 in 2004-which would be the age cohort 10- 14 in 2008 — shares some features of the age 
cohorts 6- 8 and 7- 14, thus we may expect weaker ROSC impacts for this age cohort compared to the age cohort 6- 8 , and stronger ROSC impacts overall compared to the age cohort 7- 14.

\section{Estimation Results}

Table 3 provides the estimated results using equation (1). Estimation results are robust, with the sizes of the program impact coefficients $\gamma_{k t}$ being rather similar across the different models (for the same age cohorts). $\gamma_{k t}$ are highly statistically significant for the two age cohorts 6- 10 and 6- 8 but insignificant for the age cohort 7-14-which is expected given our discussion above. ${ }^{22}$ Moreover, the impacts of the ROSC projects on enrolment for the age cohort 6-8 is largest, to be followed by that for the cohort 6-10 and lastly for the cohort 7- 14. Overall, enrolment rates in GA areas are only (statistically) higher than those in non-ROSC areas in 2006, and are lower than enrolment rates in the G areas in every year for the two cohorts 6- 8 and 6- 10. The within-individual correlation coefficients $\rho$ range from 0.25 to 0.54 and are strongly statistically significant, indicating that it is necessary to include the child random-effects component in our model.

Since a linear probability model is used, estimates can just be read off of the coefficients. For example, a child in the age cohort 6- 10 residing in the $\mathrm{G}$ areas is 12 percent more likely to be enrolled in school in 2006 , but a child in the age cohort 6- 8 residing in the $\mathrm{G}$ areas is 19 percent more likely to be enrolled in school in the same year.

Other variables have the usually expected impacts on enrolment. Controlling for other factors, older children are more likely to be enrolled in school, but age has a nonlinear

\footnotetext{
${ }^{22}$ As a robustness check, we also extend the estimation sample to include year 2009 and estimation results (not shown) are very similar. In particular, the G intervention has highly statistically significant impacts for this year.
} 
impact on enrolment. Children living in wealthier households or households with more education levels (as represented by the years of schooling for the most educated household member) have higher enrolment probabilities. On the other hand, households with large sizes have negative impacts on enrolments, but this relationship should be interpreted as correlational rather than causal because of the well-known quantity-quality tradeoff between family sizes and children's education achievement (see, for example, Becker and Lewis, 1973). While children living in richer villages are 16 percent more likely to enroll in school, this is only marginally significant at the 10 percent level, and other village characteristics are not statistically significant in all the regressions.

Interestingly, girls are around 10 percent more likely to be enrolled in school than boys for all the three age cohorts, controlling for other factors. Thus we estimate equation (1) separately for girls and boys and show estimation results in Table 4. To save space, only the program impact coefficients are shown, and the coefficients for other control variables are suppressed. ${ }^{23}$

Consistent with the results in Table 3, ROSC has the strongest impacts on the age cohort 6- 8 for both boys and girls, and has stronger impacts on girls than boys. For example, for girls in the age cohort 6-10, ROSC has strongly statistically significant impacts in both the G and GA areas in 2006. However, the impacts appear to be strongest in earlier years (i.e., 2006) for girls and later years (i.e. 2008) for boys. In 2006, the GA intervention also has some impacts on enrolment for girls in the age cohort 7- 14, although these impacts are marginally significant at the 10 percent level. Still, where the

\footnotetext{
${ }^{23}$ Perhaps the most interesting result is that the share of villagers having passed Grade 5 or higher is highly statistically significant and has positive effects in the regressions for girls but statistically insignificant in the regressions for boys.
} 
impacts are statistically significant, those in the $G$ areas are consistently stronger than those in the GA areas.

We turn to examine the impacts of the ROSC program on student test scores in the next section.

\section{IV.2. Impacts of ROSC Program on Test Scores Empirical Model}

Given that the provision of ROSC schools represents a shock to the supply of schools in an area, it is natural to investigate the impacts of ROSC by interacting dummy variables indicating ROSC areas with the year dummy variables in the previous Section. However, a similar modeling approach for test scores may not provide a good estimate of the impacts of ROSC schools since averaged test scores for all the students in an area can be a noisy measurement. Thus in this Section we examine the gains in test scores over time for students going to ROSC schools versus those for students attending non-ROSC by directly interacting dummy variables indicating ROSC schools with the year dummy variables.

Since the characteristics of ROSC schools are fundamentally different from those of other formal primary schools, ${ }^{24}$ we make two important assumptions to investigate the impacts of ROSC schools on student test scores

i. school choice is not available for most children in Bangladesh, and

ii. the differences between ROSC schools and non-ROSC schools can be controlled for with the observed school characteristics in our survey.

Given the previous studies on (religious) school choice in Bangladesh (see, for example, Asadullah, Chaudhury, and Dar, 2007), ${ }^{25}$ we acknowledge that the first

\footnotetext{
${ }^{24}$ As discussed in a previous section, ROSC schools have only one teacher and are mostly newly built schools.
} 
assumption would not be true in practice whenever students (or strictly speaking, their parents) can decide whether they go to a ROSC school or a non-ROSC school. In fact, from Table 2, we know that students attending ROSC schools generally have lower academic performance (as measured by standardized test scores) compared to students attending non-ROSC schools. When important household characteristics were compared between these two types of students, students attending ROSC schools are found to come from poorer and less well-educated households (Table 2).

However, since we do not have any good instruments in the survey to identify which students would be selected into which schools, our estimated coefficients on the ROSC schools variables (including the interacted terms between these variables and the year dummy variables) would be biased. But fortunately, given the selection of academically weaker students with less advantaged backgrounds into ROSC schools, it is rather straightforward to show that the estimated coefficients on the ROSC schools variables are biased downward rather than upward.

Indeed, assume that student test scores are a function of just the school type students attend and student innate ability and can be estimated using the following model

$$
T=\alpha+\not P+\theta A+\varepsilon
$$

where $\mathrm{T}$ is student test score, $\mathrm{P}$ is the school type (here ROSC schools), $\mathrm{A}$ is student innate ability, $\varepsilon$ is the error term, and all the subscripts are omitted for simplicity. Again the impact of ROSC schools on student test scores is measured by the coefficient $\gamma$. Note that in this model, $\theta$ is assumed to be positive (i.e. students with more ability have higher

\footnotetext{
${ }^{25}$ But note that Asadullah, Chaudhury and Dar (2007) do not find that, conditional on socio-economic background, religious school choice at the secondary level results in significant difference in student test scores. Another study on religious school choice for Indonesia by Newhouse and Beegle (2006) find similar results.
} 
test scores), and the correlation between $\mathrm{P}$ and $\mathrm{A}$ is negative or $\operatorname{cov}(P, A)<0$ (i.e. academically weaker students are more likely to attend ROSC schools, which are shown in Table 2). Since student innate ability is unobserved, and A cannot be included in the regression, our estimate $\hat{\gamma}$ of $\gamma$ is biased, and it is in fact (Greene, 2008, p. 134)

$E(\hat{\gamma} \mid P, A)=\gamma+\frac{\operatorname{cov}(P, A)}{\operatorname{var}(P)} \theta$. Since $\operatorname{cov}(P, A)<0, \operatorname{var}(P)>0$, and $\theta>0$, the second term in this expression is negative. Thus, our estimate $\hat{\gamma}$ of $\gamma$ is biased downward.

Thus, any estimated impacts of ROSC schools would represent the lower bounds of the true impacts. And it is perhaps reasonable to make the second assumption with a number of control variables on school characteristics that we use.

With some minor changes in notation, we can evaluate the impacts of ROSC schools on student learning outcomes using a model which is similar to, although somewhat simpler than, equation (1). However, the school (and student) questionnaires are slightly different from the household questionnaires, thus the explanatory variables are slightly different as described below. The model is an intention-to-treat (ITT) model and assumed to be

$$
T_{i s t}=\alpha+\sum_{k=1}^{K} \beta_{k} P_{k}+\delta Y+\sum_{k=1}^{K} \gamma_{k} P_{k} * Y+\eta Z_{i s}+\mu_{i}+\varepsilon_{i s t}
$$

where the variables are defined as follows

$\alpha:$ constant term

$T_{i s t}$ : learning outcomes, as measured by standardized test scores, for child i in school s at time $\mathrm{t}$ 
$P_{k}$ : program school, with $\mathrm{k}=1,2 . P_{1}$ being the Grant $(\mathrm{G})$ schools and $P_{2}$ being the Grant+ Allowance (GA) schools. The reference category is the non-ROSC schools in nonROSC areas (pure control group).

$Y$ : year dummy variable, which equals 1 for the year 2009 and 0 for the year 2006

$Z_{i s}$ : other control variables including individual, household, and school characteristics obtained from the follow-up survey.

Individual characteristics include student gender and age. Household characteristics include parental literacy, household size, and household living standards as measured by a housing asset index. ${ }^{26}$ School characteristics include the time it takes each student to get to school, the frequency of homework assignment in English and Mathematics for each student, the number of days the school was open in the last two weeks, the condition of school classrooms, the condition of classroom blackboards, and school infrastructure such as whether the school has a toilet, an alphabetic chart, a number chart, electricity or water. The child random effects $\mu_{i}$, the random error term $\varepsilon_{i s t}$, and the within-individual correlation $\rho$ are defined in a similar way to equation (1). ${ }^{27}$ Also similar to equation (1), standard errors are clustered at the individual level to address any possible heterogeneity in the error terms.

Again, the most interesting coefficients in equation (2) are $\gamma_{k}$, which are the coefficients on the treatment variables $P_{k} * Y$ obtained by interacting the program school

\footnotetext{
${ }^{26}$ We use a housing asset index since the student questionnaire does not contain a household consumption module which can allow calculation of household expenditures. This asset index is the first principal component of household assets such as television, fan, bicycle, phone, and access to electricity.

${ }^{27}$ Again, estimation results using a student fixed-effects model (not shown) are very similar to the randomeffects model. Hausman tests do not reject the null of no difference between these two models, except for math scores. Furthermore, since all the time-invariant variables including student and school characteristics will be washed out in the student fixed-effects model, we prefer to use the random-effects model.
} 
variables and the year variables. These coefficients represent the treatment impacts on test scores in 2009 compared to 2006 for students attending different types of school. In other words, these coefficients measure the relative gains in test scores for ROSC schools compared to non-ROSC schools in non-ROSC areas (ITT sample) over time.

\section{Estimation Results}

Estimation results are provided in Table 5 for the impacts of ROSC schools ( $\mathrm{G}$ schools and GA schools) on test scores compared to non-ROSC schools. The coefficients on the interacted terms between $\mathrm{G}$ schools and GA schools and the year dummy variable have mixed signs, although they are mostly positive. However, these coefficients are small in size and not statistically different from zero across all models. This implies that, both $\mathrm{G}$ schools and GA schools have similar impacts on the gains in student test scores as nonROSC schools. In other words, during 2006- 2009, ROSC schools are performing as well as non-ROSC schools in boosting student test scores. ${ }^{28}$

Given the lower starting points in test scores for students attending ROSC schools, especially GA schools (Table 2), and that ROSC schools are much smaller and more recently established than non-ROSC schools, this indicates perhaps no small achievement of the ROSC project. In particular, as discussed above, since the true impacts of ROSC schools are underestimated, these impacts are just conservative estimates.

\footnotetext{
${ }^{28}$ It is interesting to see that there is not much difference between the impacts of G and GA schools on test scores, although $\mathrm{G}$ schools have somewhat stronger effects on enrolment as shown in the previous Section. We believe this can be explained by two main reasons. First, during the project implementation, $G$ schools are also found to provide some allowances to students, thus effectively making them similar to GA schools. Second, there is evidence that allowances to students are not efficiently targeted toward the poorest through non-optimal project management which can contaminate the original project design. See Sarr et al. (2010) for more details and also the next footnote.
} 
Other variables, except for student gender, have the expected impacts. Students coming from wealthier households and/ or having literate parents have higher test scores. The longer students live from school, the more likely they have lower test scores; however this is mostly marginally significant at the 10 percent level. While the frequency of math homework has no statistically significant impact on test scores, more English homework can improve math test scores by 0.2 standard deviations, perhaps suggesting some complementary impacts of verbal skills on math skills. School with better blackboards or with number charts or with water has positive impacts on both Bangla and math test scores. For example, a number chart can increase math scores by as much as 0.2 standard deviations. But it is somewhat puzzling that alphabetic charts can somehow reduce student math scores.

It is interesting to note in Table 5 that girls have around 0.1 standard deviations higher gains in Bangla test scores than boys. However, girls do not have higher math scores than boys. To further investigate these gender differences, we rerun the same regressions in Table 5 separately for girls and boys and provide estimation results in Table 6. These results show that in general there is no difference in the impacts of ROSC schools on test scores for boys or girls, although girls studying at GA schools appear to have higher math test scores (which are marginally significant at the 11 percent level).

\section{Robustness Checks}

Tests Taken at School versus at Home

As discussed in the previous section, around 70 percent of the children with both baseline and follow-up test scores took the follow-up test at school, and the remaining children took this test at home. It can be argued that the environment under which the test 
was taken can affect student test scores in various ways (e.g. students may be more focused at school or lighting conditions may be different between school and home). Thus as robustness check, we drop all the children that took tests at home and rerun the estimations in Table 5. Estimation results (not shown) indicate no difference from those in Table 5, suggesting that our results are robust to the place where the tests were taken.

\section{Student Transfer}

Is it possible that parents may respond to the incentives offered in the ROSC schools (e.g. student allowances at GA schools) by withdrawing their children from other schools and enroll them in ROSC schools? Our calculation shows that around 30 percent of children that were enrolled in ROSC schools had been enrolled in some other primary or Madrasa schools before. In such cases, this can increase the test scores at ROSC schools and bias our estimates upward if these students have better academic ability, and bias our estimates downward vice versa. To check on this hypothesis, we drop all the children in the estimation sample who had been attending non-ROSC schools before enrolling in ROSC schools and re-run the estimation in Table 5. Estimation results (not shown here), however, are not different from the previous results, thus indicate our results are robust to including or excluding these transfer students who had been enrolled in non-ROSC schools prior to attending ROSC schools.

\section{Impact Heterogeneity for Student Ability}

As shown in Figures 1 and 2 above, the gains in test scores appear to vary for students with different baseline scores, especially in GA schools compared to non-ROSC schools. 
To further investigate this hypothesis, we divide student performance in the baseline into four quartiles, interact the four dummy variables indicating these quartiles with the treatment variables, and re-run the estimation in Table 5. Estimation results (Table 7) show that, while there is almost no difference over time between weak and average students (quartiles 1 and 2) in both ROSC and non-ROSC schools, better-performing students (quartiles 3 and 4) in the baseline at GA schools indeed improve more compared to their peers at non-ROSC schools. These gains range from 0.2- 0.3 standard deviations for the combined test scores to 0.3- 0.4 standard deviations for Bangla and math scores. These results suggest that GA schools did a better job in raising the test scores for better students compared to other schools.

\section{Other Program Effects ${ }^{29}$}

As shown above, the ROSC program has positive impacts on both enrolment and test scores. But do these impacts affect non-ROSC schools in the program areas in any way? To investigate this question, we use a more general form of equation (2), which is

$$
T_{i s t}=\alpha+\sum_{k=1}^{K} \beta_{k} P_{k}+\delta Y+\sum_{k=1}^{K} \gamma_{k} P_{k} * Y+\eta Z_{i s}+\mu_{i}+\varepsilon_{i s t}
$$

\footnotetext{
${ }^{29}$ We also examined directly the hypothesis that the ROSC project may have different impacts on school enrolment rates in GA areas versus G areas, as well as test scores at GA schools versus G schools, by estimating the following modified version of equation (2)

$T_{i s t}=\alpha+\beta P_{G A}+\delta Y+\gamma P_{G A} * Y+\eta Z_{i s}+\mu_{i}+\varepsilon_{i s t}$

where $\mathrm{P}_{\mathrm{GA}}$ is a dummy variable indicating Grant+Allowance schools and the reference category is the Grant schools. Estimation results (not shown here) indicate that the $G$ areas have stronger impacts on raising enrolment for the age cohorts 6-10 and 6- 8 than the GA areas do. However, there is no difference between $\mathrm{G}$ and GA schools' impacts on test scores, suggesting that over time, the GA schools have a similar impact on student test scores as the G schools. These results stand in in contrast to the oft-cited positive impacts of monetary incentives on student attendance and performance in the conditional cash transfer literature (see, for example, Fiszbein et al., 2009). While our estimates in fact points to the somewhat stronger impacts on enrolment and spillover effects from $\mathrm{G}$ schools, we believe this can be influenced by project implementation and may not reflect the true impacts of the original design. See also our preceding footnote.
} 
The variables are defined as in equation (2) above, except for the change to the variable $P_{k}$ representing program schools, with $\mathrm{k}=1,2,3,4 ; P_{1}$ being the Grant $(\mathrm{G})$ schools, $P_{2}$ the Grant+ Allowance (GA) schools, $P_{3}$ non-ROSC schools in $\mathrm{G}$ areas, and $P_{4}$ non-ROSC schools in GA areas. The reference category is the non-ROSC schools in non-ROSC areas.

Estimation results (Table 8) show that students attending non-ROSC schools in ROSC areas generally improve their test scores more than students attending non-ROSC schools in non-ROSC areas, with the improvement ranging from 0.3 standard deviations in math scores to 0.53 standard deviations in Bangla scores and combined scores. In particular, students attending non-ROSC schools in G areas gain more than those attending nonROSC schools in GA areas. The gains for the former group are from twice more than to almost three times higher than those for the latter group.

There are two possible explanations for this difference. First, ROSC schools may have done a good job in attracting both out-of-school children and the weaker students in ROSC areas-who would have gone to non-ROSC school in ROSC areas in the absence of ROSC schools - thus leaving non-ROSC schools in ROSC areas with better students. This hypothesis appears to be consistent with the results in Table 3, where ROSC schools are found to significantly raise school enrolment in ROSC areas. Second, the presence of ROSC schools, especially G schools, may increase the efficiency for non-ROSC schools in ROSC areas, perhaps most likely through increased competition for student enrolment. This hypothesis would be consistent with Hoxby (2000, 2002)'s argument that public schools are likely to respond to competition from choice schools (ROSC schools in our case) by raising their student achievement. 
At the same time, there is almost no change to the test scores for student attending ROSC schools versus those attending non-ROSC schools in non-ROSC areas, which is reassuring and confirms the robustness of the results discussed earlier in Table 5.

\section{Relative Efficiency of ROSC Schools}

ROSC schools appear to operate more efficiently than government primary (GP) schools in several aspects. ${ }^{30}$ First, ROSC schools are organized around a single teacher in one classroom, thus they exhibit low operating costs compared to GP schools. ROSC schools often rent a room in a house to serve as a classroom in which multiple grades are being taught by the same teacher.

Second, teacher salaries-which usually represent the lion's share of operational expenses for the education sector in developing countries-are also much smaller in ROSC schools. While the average annual government expenditure per student at ROSC schools is around Taka 1,489 (Sarr et al., 2010), the corresponding figure for GP schools is more than twice higher at Taka $3,108(\mathrm{GOB}, 2009) .{ }^{31}$ Furthermore, the majority of ROSC teachers $(85 \%)$ earn a monthly salary less than Taka 1,200 and ROSC teachers' monthly salaries are rarely higher than Taka 1,500 (ROSC Project Office Unit, 2009). This monthly salary is more than six times less than the monthly salary of Taka 7,515 for the least qualified teachers (who are assistant teachers without a Primary Training Institute (PTI) certificate), and the monthly salary of Taka 7,950 for the average teachers with a PTI certificate.

\footnotetext{
${ }^{30}$ We do not have data on costs for other non-ROSC schools including Madrasa schools, but the majority (95\% or more) of non-ROSC schools in our estimation samples are government primary schools.

${ }^{31}$ These numbers are recurrent unit costs and the former figure is for 2009 and the latter for 2008.
} 
Notably, while the student-teacher ratio in ROSC schools (35 students per teacher) is smaller than the corresponding figure (52 students per teacher) for GP schools, ${ }^{32}$ this difference is still disproportionate to the wide disparity in teacher salaries.

Third, compared to GP schools, the management of ROSC schools is more decentralized with Community Management Centers (CMC) working closely with local NGOs, ${ }^{33}$ thereby enhancing the accountability in school management. Low teacher absenteeism-less than 5 percent-is another characteristic of ROSC schools (ROSC Monitoring Report 2009). Among teachers present in school during the survey visit, over $80 \%$ were actually teaching.

At the same time, students attending ROSC schools have equally substantially improved their performance in Bangla and Math tests as well as their peers at non-ROSC schools, and academically stronger students at GA schools have even improved more. This relatively good performance of ROSC schools despite their low operating costs seems to suggest that they are more efficient compared to non ROSC schools. ${ }^{34}$

It may be useful to reflect on the driving factors behind this efficiency at ROSC schools. Unsurprisingly, the advantages of ROSC schools are built upon the same characteristics of its prototype-the successful BRAC school model. In addition to the features discussed earlier (e.g., BRAC schools have smaller class sizes and more contact hours), two features that are often missing in GP schools can be highlighted.

\footnotetext{
${ }^{32}$ An obvious implication of this is that ROSC students are more likely to get more attention from their teacher than their peers in non-ROSC schools. However, while there is no ROSC (or BRAC) secondary school, it should be noted that in the Bangladeshi context, smaller class sizes at the secondary school level may not lead to higher test scores (Asadullah, 2005).

33 These NGOs assist the ROSC school in identifying out-of-school children and hard-to-reach children, ensuring their enrolment and attendance, and support CMCs in running the ROSC schools.

${ }^{34}$ In fact, evidence elsewhere shows that other models of non-formal schools in Honduras, Ghana, and Mali are also more cost-effective than their public counterparts (DeStefano et al., 2006).
} 
First, BRAC schools are built and continuously improved upon the principle of "listening to the people" since BRAC itself is "constantly soliciting and acting on feedback, criticism, and suggestions" (Ahmed and French, 2006). This spirit results in the dynamism and flexibility behind the BRAC school model, which has now been adopted in a number of countries in Africa and Asia including Afghanistan, Liberia, Pakistan, Tanzania, Southern Sudan, and Sri Lanka. In fact, the non-formal primary education program is just an area among several others such as silk worms, microfinance, solar panels, maternal health, recycled paper, and high fashion in which BRAC operates projects based on a social entrepreneurship approach (BRAC, 2009). ROSC schools understandably inherit this dynamism through a highly decentralized system with strong community participation in management.

Second, the quality of teachers at BRAC schools is perceived to be higher than that of their GP counterparts in several ways. ${ }^{35}$ Firstly, BRAC teachers are recruited from the same local community as their students and have a close relationship with their students, who they are responsible for during the full three-year (or four- year) cycles. In contrast to GP teachers who may either neglect or resort to corporal punishment for their students, BRAC teachers are affectionate to their students (Chabbot, 2006). Secondly, although BRAC teachers' formal education levels are often limited to high-school level (i.e., nine or ten years of schooling) and lower than those of GP teachers, their skills are constantly developed through needs-based and practical refresher training which occurs monthly. ${ }^{36}$ In

\footnotetext{
35 While raising a number of issues about the effectiveness of school resources, Hanushek strongly advocates the role of teacher quality in raising educational outcomes. See, for example, Hanushek (2011) and Hanushek and Rivkin (2006).

${ }^{36}$ It is interesting to note that recent evidence for the US suggests that neither holding a college major in education nor more advanced degree is associated with elementary and middle school teaching effectiveness (Chingos and Peterson, 2011).
} 
addition, BRAC teachers also have much stronger support and supervision than their GP counterparts (Haiplik, 2004). And thirdly, BRAC teachers are highly motivated, perhaps not least because of the enhanced respect and standing in their communities obtained by their teaching status.

\section{Conclusion}

In this paper we investigate the impacts of ROSC schools versus other types of schools on student enrolment and test score gains over time. This is a unique program where the GOB for the first time experimented with bringing into the public system the well-known NGO-run BRAC school model. We found that ROSC schools increase enrolment probability between 9 and 18 percent and perform as well as non-ROSC schools in raising test scores. In particular, better performing students attending GA schools improve their test scores by around 0.2- 0.4 standard deviations compared to other schools.

Furthermore, ROSC schools appear to have positive externalities on test scores for students attending non-ROSC schools in program areas. These findings are robust to different model assumptions and specifications. Given the selection of academically weaker students coming from less advantaged households into ROSC schools, we also show that our estimated impacts are conservative (i.e., biased downward). Notably, despite this impressive performance ROSC schools, among other things, have much lower operational costs than GP schools.

Given mixed results about the effects of different components of school resources, these results about the positive impacts of ROSC schools appear quite encouraging. While future research may focus on disentangling and quantifying further the particular 
characteristics that make ROSC (or BRAC) schools stand out from other school models, our results point to the effectiveness of this non-formal school model as a comprehensive "package", whose salient characteristics include streamlined operations, high teacher quality, and a spirit of constant self-learning and self-improving.

Both the effectiveness and efficiency of the ROSC school program render it as an attractive approach to increase schooling quantity and quality, especially as the GOB plans to achieve the MDG goals of universal primary education by 2015. Our results suggest that the ROSC program can be expanded on a larger scale in Bangladesh. We also believe that these findings provide useful input for policy makers in Bangladesh and other countries that may plan to adopt a similar schooling model. 


\section{References}

Ahmed, Akhter U. (2006). "Evaluating the Reaching Out Of School Children Project in Bangladesh: A Baseline Study.” International Food Policy Research Institute, IFPRI, Washington, DC.

Ahmed, Manzoor. (2008). "Policy Options in Non-Formal Education". In William K. Cummings and James H. Williams. (Eds). "Policy-Making in Education Reforms in Developing Countries: Policy Options and Strategies". Rowman \& Littlefield Education: United States of America.

Ahmed, Salehuddin and Micaela French. (2006). "Scaling Up- The BRAC Experience". BRAC University Journal, 3(2): 35-40.

Arif, G. M. and Najam Us Saqib. (2003), "Production of Cognitive and Life Skills in Public, Private, and NGO Schools in Pakistan". Pakistan Development Review. 42: 1 (Spring 2003) pp. 1-28.

Asadullah, Mohammad Niaz. (2005). "The Effect of Class Size on Student Achievement: Evidence from Bangladesh". Applied Economics Letter, 12: 217- 221.

Asadullah, Mohammad Niaz, Nazmul Chaudhury, and Amit Dar. (2007). "Student Achievement Conditioned upon School Selection: Religious and Secular Secondary School Quality in Bangladesh.” Economics of Education Review 26(6): 648-59.

Banerjee, Abhijit V., Shawn Cole, Esther Duflo, and Leigh Linden. (2007). "Remedying Education: Evidence from Two Randomized Experiments in India." Quarterly Journal of Economics 122 (3): 1235-64.

Banerjee, Abhijit V., Rukmini Banerji, Esther Duflo, Rachel Glennerster, and Stuti Khemani. (2010). "Pitfalls of Participatory Programs: Evidence from a Randomized Evaluation in Education in India". American Economic Journal: Economic Policy, $2: 1,1-30$.

Becker, Gary, and H. G. Lewis. (1973). "On the Interaction between the Quantity and Quality of Children.” Journal of Political Economy 81: S279-288.

BRAC (Bangladesh Rural Advancement Committee). (2009). "BRAC Annual Report 2009". Available on the Internet at http://www.brac.net/oldsite/useruploads/files/bracar-2009.pdf. (Accessed in March 2011). 
Chabbot, Colette. (2006). "Meeting EFA: Bangladesh Rural Advancement Committee (BRAC) Primary Schools”. Washington DC: Academy for Education Development. www.equip123.net

Chingos, Mathew M. and Paul E. Peterson. (2011). "It's Easier to Pick a Good Teacher Than to Train One: Familiar and New Results on the Correlates of Teacher Effectiveness." Economics of Education Review, 30: 449-465.

Dang, Hai-Anh, and Halsey Rogers. (2008). "The Growing Phenomenon of Private Tutoring: Does It Deepen Human Capital, Widen Inequalities, or Waste Resources?" World Bank Research Observer 23(2): 161-200.

Data Analysis and Technical Analysis (DATA). (2010). "Public Expenditure Tracking Survey and Impact Evaluation for Reaching Out Of School Children Project (ROSC) Follow-up Survey Report". Dhaka, Bangladesh.

DeStefano, Joseph, Ash Hartwell, Audrey-marie Schuh Moore, and Jen Benbow. (2006). "A Cross-National Cost-Benefit Analysis of Complementary (Out-Of-School) Programs". Journal of International Cooperation in Education, 9(1): 71- 88.

Duflo, Esther, Pascaline Dupas, and Michael Kremer. 2010. "Pupil-Teacher Ratio, Teacher Management and Education Quality: Experimental Evidence from Kenyan Primary Schools". Mimeo, MIT.

Evans, David, Michael Kremer, and Muthoni Ngatia. (2008). "The Impact of Distributing School Uniforms on Children's Education in Kenya." Working paper, Harvard University.

Farrell, Joseph P. (2004). "The Egyptian Community Schools Program: A Case Study”. Washington DC: Academy for Education Development. www.equip123.net Farrell, Joseph P. and Ash Hartwell. (2008). "Planning for Successful Alternative Schooling: A Possible Route to Education for All”. International Institute for Education Planning research paper.

Filmer, Deon. (2007). "If You Build It, Will They Come? School Availability and School Enrolment in 21 Poor Countries." Journal of Development Studies, 43(5): 901-928.

Fiszbein, Ariel, Norbert Schady, Francisco H. G. Ferreira, Margaret Grosh, Nial Kelleher, Pedro Olinto, and Emmanuel Skoufias. (2009). "Conditional Cash Transfers: Reducing Present and Future Poverty." World Bank. Washington DC: USA. 
Glewwe, Paul, Michael Kremer, Sylvie Moulin, and Eric Zitzewitz. (2004).

"Retrospective vs. Prospective Analyses of School Inputs: The Case of Flip Charts in Kenya”. Journal of Development Economics, 74: 251- 268.

Glewwe, Paul, and Michael Kremer. (2006). "School, Teachers, and Education Outcomes in Developing Countries." In Eric A. Hanushek and Finis Welch, eds., Handbook of the Economics of Education. Amsterdam: North-Holland.

Glewwe, Paul, Michael Kremer, and Sylvie Moulin. (2009). "Many Children Left Behind? Textbooks and Test Scores in Kenya". American Economic Journal: Applied Economics 2009, 1:1, 112-135

Glewwe, Paul, Nauman Ilias, and Michael Kremer. (2010). "Teacher Incentives". American Economic Journal: Applied Economics 2 (July 2010): 205-227.

Government of Bangladesh (GOB), General Economic Division, Planning Commission. (2009). “Millennium Development Goals Needs Assessment and Costing 2009- 2015 Bangladesh". Available on the Internet at http://www.undp.org.bd/info/pub/MDG\%20Needs\%20Assessment\%20\&\%20Costing \%202009-2015\%20small.pdf (accessed in February 2011).

Haiplik, Brenda Mary. (2004). "An Educational Success Story from Bangladesh: Understanding the BRAC Non-Formal Primary Education Model and Its Teacher Training and Development System". Unpublished Ph.D. thesis, University of Toronto.

Hanushek, Erik A. (2006). "School Resources". In Eric A. Hanushek and Finis Welch, eds., Handbook of the Economics of Education. Amsterdam: North-Holland.

---. (2011). “The Economic Value of Higher Teacher Quality". Economics of Education Review, 30: 466-479.

Hanushek, Erik A. and Steven G. Rivkin. (2006). "Teacher Quality”. In Eric A. Hanushek and Finis Welch, eds., Handbook of the Economics of Education. Amsterdam: NorthHolland.

Hartwell, Ash. (2006). "Meeting EFA: Ghana School for Life". Washington DC: Academy for Education Development. www.equip123.net

Hoxby, Caroline. (2000). "Does Competition Among Public Schools Benefit Students and Tax Payers?" American Economic Review, 90(5): 1209-1238.

---. (2002). "How School Choice Affects Public School Students' Achievement”. In Paul Hill, eds. Choice with Equity. Stanford: Hoover Institution Press. 
Kremer, Michael and Alaka Holla. (2009). "Improving Education in the Developing World: What Have We Learned from Randomized Evaluations?" Annual Review of Economics, 1: 513-542.

Kremer, Michael, Edward Miguel, and Rebecca Thornton. (2009). "Incentives to Learn," Review of Economics and Statistics, 91(3): 437-456.

Khan, S.R. and Kiefer, D. (2007) "Educational Production Functions for Rural Pakistan: A Comparative Institutional Analysis", Education Economics, 15 (3): 327-342.

Greene, William. (2008). “Econometric Analysis, $6^{\text {th }}$ Edition”. New Jersey: Prentice Hall. McEwan, Patrick. (1998). "The Effectiveness of Multigrade Schools in Columbia". International Journal of Educational Development, 18(6): 435-452.

Muralidharan, Karthik and Venkatesh Sundararaman. (2009). "Teacher Performance Pay: Experimental Evidence from India". National Bureau of Economic Research Working Paper \#15323.

Newhouse, David and Kathleen Beegle. (2006). "The Effect of School Type on Academic Achievement: Evidence from Indonesia.” Journal of Human Resources 41(3): 529-57. Psacharopolous, George, Carlos Rojas, and Eduardo Velez. (1993). "Achievement Evaluation of Colombia's" Escuela Nueva": Is Multigrade the Answer?". Comparative Education Review, 37(3): 263- 276.

Sarr, Leopold Remi, Hai-Anh Dang, Nazmul Chaudhury, Dilip Parajuli, and Niaz Asadullah. (2010). "Reaching Out of Children Project Evaluation Report". South Asian Human Development Sector, World Bank.

ROSC Project Office Unit. (2009). "ROSC Monitoring Cell Report". Dhaka, Bangladesh. Sud, Pamela. (2010) “Can Non-formal Education Keep Working Children in School? A Case Study from Punjab, India", Journal of Education and Work, 23(1): 1 - 26. Sukontamarn, Pataporn. (2006). "The Entry of NGO Schools and Girls' Educational Outcomes in Bangladesh". Working paper, University of Adelaide.

World Bank. (2011). World Development Indicators Online. Available on the Internet at http://data.worldbank.org/indicator/PA.NUS.FCRF (accessed February 2011). 
Figure 1: Distribution of Standardized Test Scores, Bangladesh 2006- 2009
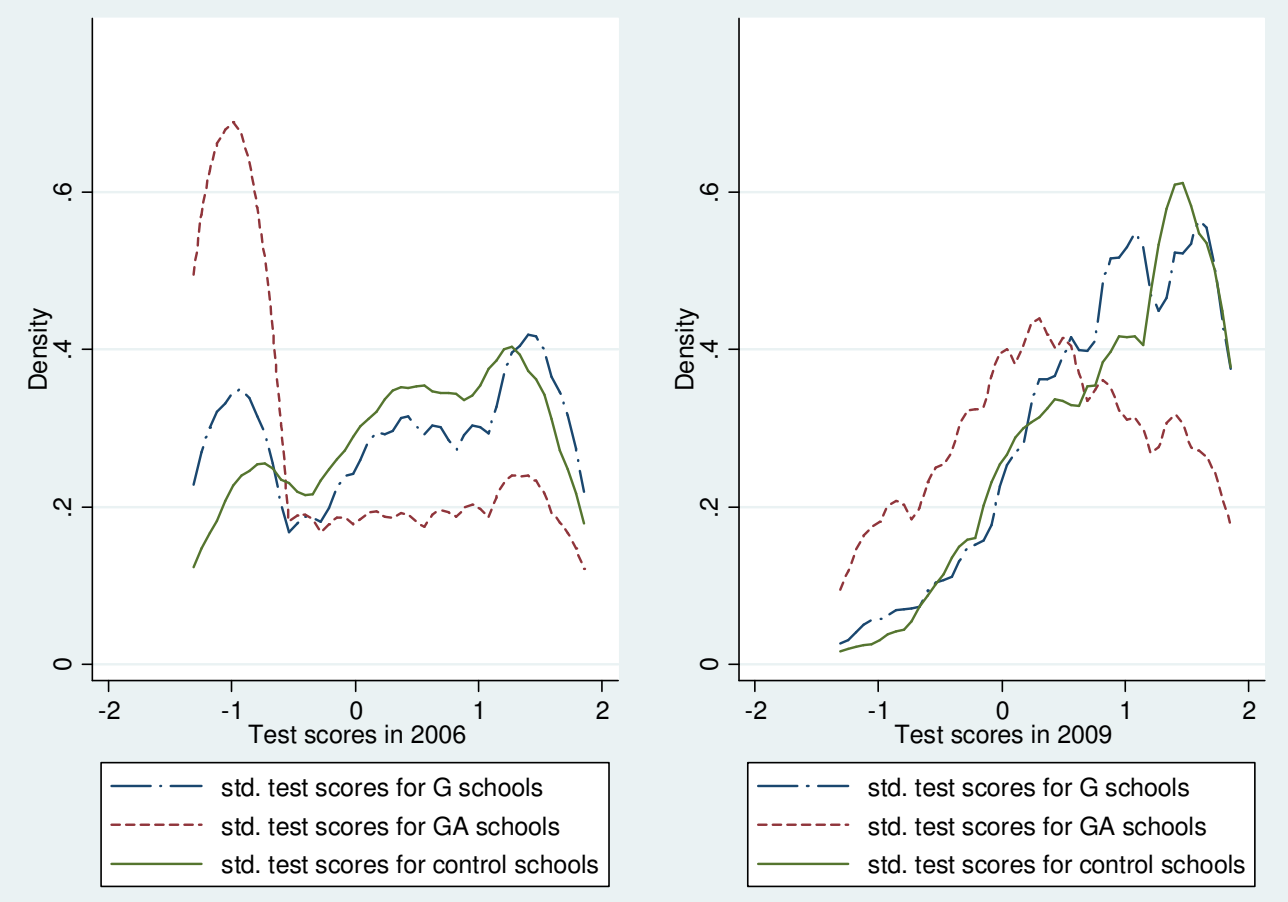
Table 1: Summary Statistics for Children Age 6- 14 in 2004 in the Panel Household Survey by Program and Non-Program Areas, Bangladesh 2006

\begin{tabular}{|c|c|c|c|c|c|}
\hline & $\begin{array}{c}\text { Non-ROSC } \\
\text { Areas }\end{array}$ & \multicolumn{2}{|c|}{ Grant Areas } & \multicolumn{2}{|c|}{$\begin{array}{c}\text { Grant+ Allowance } \\
\text { Areas }\end{array}$} \\
\hline & Mean (Sd) & \multicolumn{2}{|c|}{ Mean (Sd) } & \multicolumn{2}{|c|}{ Mean (Sd) } \\
\hline \multirow[t]{2}{*}{ Enrolled in school in 2004} & 0.87 & 0.85 & -0.01 & 0.85 & -0.02 \\
\hline & $(0.34)$ & $(0.35)$ & & $(0.36)$ & \\
\hline \multirow[t]{2}{*}{ Age } & 11.31 & 11.02 & -0.29 & 11.06 & -0.25 \\
\hline & $(2.23)$ & $(2.34)$ & & $(2.23)$ & \\
\hline \multirow[t]{2}{*}{ Female } & 0.47 & 0.47 & -0.00 & 0.50 & 0.03 \\
\hline & $(0.50)$ & $(0.50)$ & & $(0.50)$ & \\
\hline \multirow[t]{2}{*}{ HH's most edu. member's yrs of schooling } & 6.62 & 6.12 & $-0.50^{*}$ & 5.73 & $-0.89 * *$ \\
\hline & $(2.97)$ & $(3.38)$ & & $(3.12)$ & \\
\hline \multirow[t]{2}{*}{ Household size } & 5.12 & 4.91 & -0.21 & 5.12 & 0.00 \\
\hline & $(1.51)$ & $(1.45)$ & & $(1.33)$ & \\
\hline \multirow[t]{2}{*}{ Log of per capita monthly exp. } & 7.25 & 7.16 & $-0.09 * *$ & 7.13 & $-0.12 * *$ \\
\hline & $(0.45)$ & $(0.40)$ & & $(0.43)$ & \\
\hline \multirow[t]{2}{*}{ Share of village households w. electricity } & 0.39 & 0.45 & $0.06^{* *}$ & 0.41 & 0.01 \\
\hline & $(0.30)$ & $(0.23)$ & & $(0.24)$ & \\
\hline \multirow[t]{2}{*}{ Average cultivable land area } & 58.68 & 101.54 & $42.86^{* *}$ & 53.78 & $-4.90 * *$ \\
\hline & $(18.81)$ & (41.35) & & $(29.54)$ & \\
\hline \multirow[t]{2}{*}{$\begin{array}{l}\text { Share of cultivable land area under irriagation in } \\
\text { winter }\end{array}$} & 0.37 & 0.47 & $0.10^{* *}$ & 0.38 & 0.02 \\
\hline & $(0.12)$ & $(0.18)$ & & $(0.17)$ & \\
\hline \multirow[t]{2}{*}{$\begin{array}{l}\text { Share of village hhs that consumed/ purchased fish or } \\
\text { meat in past } 7 \text { days }\end{array}$} & 0.84 & 0.81 & $-0.03 * *$ & 0.81 & $-0.02 *$ \\
\hline & $(0.20)$ & $(0.10)$ & & $(0.14)$ & \\
\hline \multirow[t]{2}{*}{ Share of villagers passing Grade 5 or higher } & 0.39 & 0.33 & $-0.05 * *$ & 0.31 & $-0.07 * *$ \\
\hline & $(0.05)$ & $(0.07)$ & & $(0.07)$ & \\
\hline No of children & 219 & 302 & & 420 & \\
\hline \multicolumn{6}{|c|}{ Note: 1. Standard deviations in parentheses; ${ }^{*} p<.1,{ }^{* *} p<0.05$} \\
\hline \multicolumn{6}{|c|}{ 2. Significance levels are for two-tailed t tests between G or GA areas and non-ROSC areas. } \\
\hline \multicolumn{4}{|c|}{ 3. Except for the enrolment variables, all characteristics were in 2006.} & & \\
\hline
\end{tabular}


Table 2: Summary Statistics for Children with Test Scores by Program and NonProgram Schools, Bangladesh 2009

\begin{tabular}{|c|c|c|c|c|c|}
\hline & \multirow{2}{*}{$\begin{array}{c}\text { Non-ROSC Schools } \\
\text { in Non-ROSC areas } \\
\text { Mean (Sd) }\end{array}$} & \multicolumn{2}{|c|}{ G Schools } & \multicolumn{2}{|c|}{ GA Schools } \\
\hline & & Mean (Sd) & Dif. & Mean (Sd) & Dif. \\
\hline \multirow[t]{2}{*}{ Bangla Scores in 2006 (percent) } & 55.94 & 52.92 & -3.02 & 33.27 & $-22.67 * *$ \\
\hline & $(33.28)$ & $(36.42)$ & & (37.10) & \\
\hline \multirow[t]{2}{*}{ Math Scores in 2006 (percent) } & 55.30 & 54.56 & -0.74 & 43.54 & $-11.76^{* *}$ \\
\hline & (32.69) & (34.34) & & (39.03) & \\
\hline \multirow[t]{2}{*}{ Combined Scores in 2006 (percent) } & 55.70 & 53.53 & -2.17 & 37.12 & $-18.58 * *$ \\
\hline & $(27.34)$ & (30.04) & & (33.63) & \\
\hline \multirow[t]{2}{*}{ Age } & 10.87 & 11.67 & $0.80^{*}$ & 11.57 & 0.70 \\
\hline & (6.07) & (3.51) & & (5.78) & \\
\hline \multirow[t]{2}{*}{ Female } & 0.53 & 0.45 & $-0.08 * *$ & 0.49 & -0.04 \\
\hline & $(0.50)$ & $(0.50)$ & & $(0.50)$ & \\
\hline \multirow[t]{2}{*}{ Household asset index } & 0.60 & 0.17 & $-0.43^{* *}$ & -0.46 & $-1.06 * *$ \\
\hline & $(1.66)$ & $(1.71)$ & & $(1.39)$ & \\
\hline \multirow[t]{2}{*}{ Literate parent(s) } & 0.70 & 0.51 & $-0.19 * *$ & 0.53 & $-0.17^{* *}$ \\
\hline & $(0.46)$ & $(0.50)$ & & $(0.50)$ & \\
\hline \multirow[t]{2}{*}{ Female head } & 0.10 & 0.09 & -0.01 & 0.09 & -0.01 \\
\hline & $(0.30)$ & $(0.28)$ & & $(0.28)$ & \\
\hline \multirow[t]{2}{*}{ Household size } & 4.89 & 4.82 & -0.07 & 5.09 & 0.2 \\
\hline & $(1.51)$ & (1.43) & & $(2.13)$ & \\
\hline \multirow[t]{2}{*}{ Time to school } & 12.79 & 7.74 & $-5.05^{* *}$ & 6.21 & $-6.58^{* *}$ \\
\hline & $(10.07)$ & (6.53) & & (6.24) & \\
\hline \multirow[t]{2}{*}{ English homework most of the week } & 0.97 & 0.92 & $-0.05^{* *}$ & 0.76 & $-0.21 * *$ \\
\hline & $(0.16)$ & $(0.27)$ & & $(0.43)$ & \\
\hline \multirow[t]{2}{*}{ Math homework most of the week } & 0.96 & 0.95 & -0.01 & 0.77 & $-0.19 * *$ \\
\hline & $(0.19)$ & $(0.22)$ & & $(0.42)$ & \\
\hline \multirow[t]{2}{*}{ No of days school open last 2 weeks } & 11.08 & 11.33 & $0.25 * *$ & 10.03 & $-1.05^{* *}$ \\
\hline & $(1.43)$ & $(1.81)$ & & $(2.36)$ & \\
\hline \multirow[t]{2}{*}{ Condition of blackboard } & 3.00 & 2.87 & $-0.13^{* *}$ & 2.78 & $-0.22^{* *}$ \\
\hline & $(0.00)$ & $(0.44)$ & & $(0.64)$ & \\
\hline \multirow[t]{2}{*}{ School has toilet } & 0.93 & 0.54 & $-0.39 * *$ & 0.32 & $-0.61^{* *}$ \\
\hline & $(0.25)$ & $(0.50)$ & & $(0.47)$ & \\
\hline \multirow[t]{2}{*}{ School has alphabetic chart } & 0.54 & 0.34 & $-0.2^{* *}$ & 0.27 & $-0.27^{* *}$ \\
\hline & $(0.50)$ & $(0.47)$ & & $(0.45)$ & \\
\hline \multirow[t]{2}{*}{ School has number chart } & 0.54 & 0.15 & $-0.39 * *$ & 0.19 & $-0.35^{* *}$ \\
\hline & $(0.50)$ & $(0.36)$ & & $(0.39)$ & \\
\hline \multirow[t]{2}{*}{ School has electricity } & 0.67 & 0.10 & $-0.57^{* *}$ & 0.12 & $-0.55^{* *}$ \\
\hline & $(0.47)$ & $(0.30)$ & & $(0.32)$ & \\
\hline \multirow[t]{2}{*}{ School has water } & 0.94 & 0.76 & $-0.18^{* *}$ & 0.41 & $-0.53^{* *}$ \\
\hline & $(0.24)$ & $(0.43)$ & & $(0.49)$ & \\
\hline No of children & 217 & 833 & & 782 & \\
\hline \multicolumn{6}{|c|}{ Note: 1 . Standard deviations in parentheses. The differences are between program schools and control schools } \\
\hline \multicolumn{6}{|c|}{ 2. Significance levels are for two-tailed t tests with unequal variances between G or GA schools and } \\
\hline non-ROSC schools; *p<.1, **p<0.05. & & & & & \\
\hline 3. Except for the test scores, all chara & ristics were in 2009. & & & & \\
\hline
\end{tabular}


Table 3: Impacts of ROSC Project on School Enrolment, Bangladesh 2009

\begin{tabular}{|c|c|c|c|c|c|c|c|c|c|}
\hline & \multicolumn{3}{|c|}{ Age 6- 10 in 2004} & \multicolumn{3}{|c|}{ Age 6- 8 in 2004} & \multicolumn{3}{|c|}{ Age 7- 14 in 2004} \\
\hline & Model 1 & Model 2 & Model 3 & Model 4 & Model 5 & Model 6 & Model 7 & Model 8 & Model 9 \\
\hline \multirow[t]{2}{*}{ G areas* 2006} & $0.117^{* * *}$ & $0.121^{* * *}$ & $0.121^{* * *}$ & $0.188^{* * *}$ & $0.191^{* * *}$ & $0.191^{* * *}$ & 0.012 & 0.016 & 0.016 \\
\hline & $(0.043)$ & $(0.043)$ & $(0.043)$ & $(0.056)$ & $(0.056)$ & $(0.056)$ & $(0.034)$ & $(0.034)$ & $(0.034)$ \\
\hline \multirow[t]{2}{*}{ GA areas* 2006} & $0.089 * *$ & $0.092^{* *}$ & $0.092^{* *}$ & $0.118^{* *}$ & $0.121^{* *}$ & $0.121^{* *}$ & 0.042 & 0.044 & 0.044 \\
\hline & $(0.037)$ & $(0.037)$ & $(0.037)$ & $(0.048)$ & $(0.048)$ & $(0.048)$ & $(0.029)$ & $(0.029)$ & $(0.029)$ \\
\hline \multirow[t]{2}{*}{ G areas* 2007} & 0.071 & 0.075 & 0.074 & $0.165^{* * *}$ & $0.164 * * *$ & $0.161^{* * *}$ & -0.031 & -0.023 & -0.024 \\
\hline & $(0.051)$ & $(0.051)$ & $(0.051)$ & $(0.062)$ & $(0.062)$ & $(0.062)$ & $(0.043)$ & $(0.042)$ & $(0.043)$ \\
\hline \multirow[t]{2}{*}{ GA areas* 2007} & 0.021 & 0.026 & 0.017 & 0.089 & 0.089 & 0.076 & -0.019 & -0.018 & -0.024 \\
\hline & $(0.046)$ & $(0.046)$ & $(0.047)$ & $(0.056)$ & $(0.056)$ & $(0.057)$ & $(0.038)$ & $(0.038)$ & $(0.038)$ \\
\hline \multirow[t]{2}{*}{ G areas* 2008} & $0.117^{* *}$ & $0.120^{* *}$ & $0.120^{* *}$ & $0.179 * * *$ & $0.178^{* * *}$ & $0.175^{* * *}$ & 0.020 & 0.028 & 0.027 \\
\hline & $(0.055)$ & $(0.055)$ & $(0.055)$ & $(0.066)$ & $(0.066)$ & $(0.066)$ & $(0.047)$ & (0.046) & $(0.047)$ \\
\hline \multirow[t]{2}{*}{ GA areas* 2008} & 0.013 & 0.018 & 0.010 & 0.060 & 0.060 & 0.047 & -0.025 & -0.024 & -0.030 \\
\hline & $(0.051)$ & $(0.051)$ & $(0.052)$ & $(0.061)$ & $(0.061)$ & $(0.062)$ & $(0.043)$ & $(0.042)$ & $(0.042)$ \\
\hline \multirow[t]{2}{*}{ G areas } & $-0.145^{* * *}$ & $-0.128 * * *$ & $-0.118^{* *}$ & $-0.215^{* * *}$ & $-0.194 * * *$ & $-0.189 * * *$ & -0.042 & -0.021 & 0.013 \\
\hline & $(0.045)$ & $(0.043)$ & $(0.049)$ & $(0.059)$ & $(0.055)$ & $(0.062)$ & $(0.035)$ & $(0.034)$ & $(0.041)$ \\
\hline \multirow[t]{2}{*}{ GA areas } & $-0.098 * *$ & $-0.077^{* *}$ & -0.061 & $-0.112^{* *}$ & $-0.097^{*}$ & -0.073 & $-0.067 * *$ & -0.034 & -0.016 \\
\hline & $(0.040)$ & $(0.039)$ & $(0.042)$ & $(0.053)$ & $(0.050)$ & $(0.054)$ & $(0.033)$ & $(0.031)$ & $(0.034)$ \\
\hline \multirow[t]{2}{*}{ Year 2006} & $0.097^{* * *}$ & $0.094 * * *$ & $0.094^{* * *}$ & $0.133^{* * *}$ & $0.130 * * *$ & $0.130 * * *$ & -0.002 & -0.005 & -0.005 \\
\hline & $(0.027)$ & $(0.027)$ & $(0.027)$ & $(0.035)$ & $(0.035)$ & $(0.035)$ & $(0.021)$ & $(0.021)$ & $(0.021)$ \\
\hline \multirow[t]{2}{*}{ Year 2007} & $0.077^{* *}$ & 0.057 & 0.054 & $0.122 * * *$ & $0.111^{* *}$ & $0.112^{* *}$ & $-0.059 * *$ & $-0.093 * * *$ & $-0.100 * * *$ \\
\hline & $(0.035)$ & $(0.036)$ & $(0.036)$ & $(0.043)$ & $(0.044)$ & $(0.043)$ & $(0.029)$ & $(0.029)$ & (0.029) \\
\hline \multirow[t]{2}{*}{ Year 2008} & 0.008 & -0.012 & -0.015 & $0.081^{*}$ & 0.069 & 0.070 & $-0.142^{* * *}$ & $-0.176^{* * *}$ & $-0.183^{* * *}$ \\
\hline & $(0.039)$ & $(0.040)$ & $(0.040)$ & $(0.047)$ & $(0.047)$ & $(0.047)$ & $(0.033)$ & $(0.033)$ & $(0.034)$ \\
\hline \multirow[t]{2}{*}{ Age } & & $0.324^{* * *}$ & $0.324^{* * *}$ & & 0.565 & 0.639 & & 0.087 & 0.084 \\
\hline & & $(0.107)$ & $(0.108)$ & & $(0.421)$ & $(0.432)$ & & $(0.069)$ & $(0.069)$ \\
\hline \multirow[t]{2}{*}{ Age squared } & & $-0.017^{* * *}$ & $-0.017^{* * *}$ & & -0.030 & -0.034 & & $-0.006 * *$ & $-0.006^{* *}$ \\
\hline & & $(0.005)$ & $(0.005)$ & & $(0.023)$ & $(0.024)$ & & $(0.003)$ & $(0.003)$ \\
\hline \multirow[t]{2}{*}{ Female } & & $0.107^{* * *}$ & $0.107^{* * *}$ & & $0.096^{* * *}$ & $0.096^{* * *}$ & & $0.100 * * *$ & $0.100^{* * *}$ \\
\hline & & $(0.018)$ & $(0.018)$ & & $(0.021)$ & $(0.021)$ & & $(0.020)$ & $(0.020)$ \\
\hline \multirow[t]{2}{*}{$\begin{array}{l}\text { HH's most edu. member's yrs of } \\
\text { schooling }\end{array}$} & & $0.023 * * *$ & $0.023 * * *$ & & $0.021^{* * *}$ & $0.021 * * *$ & & $0.038 * * *$ & $0.038^{* * *}$ \\
\hline & & $(0.003)$ & $(0.003)$ & & $(0.004)$ & $(0.004)$ & & $(0.004)$ & $(0.004)$ \\
\hline Household size & & $-0.028 * * *$ & $-0.028 * * *$ & & $-0.031 * * *$ & $-0.030 * * *$ & & $-0.019 * * *$ & $-0.019 * * *$ \\
\hline & & $(0.007)$ & $(0.007)$ & & $(0.008)$ & $(0.008)$ & & $(0.007)$ & $(0.007)$ \\
\hline Log of per capita monthly exp. & & $0.090 * * *$ & $0.087^{* * *}$ & & $0.082 * * *$ & $0.079 * *$ & & $0.120 * * *$ & $0.115^{* * *}$ \\
\hline & & $(0.025)$ & $(0.026)$ & & $(0.030)$ & $(0.031)$ & & $(0.028)$ & $(0.029)$ \\
\hline $\begin{array}{l}\text { Share of village households w. } \\
\text { electricity }\end{array}$ & & & -0.085 & & & -0.067 & & & -0.088 \\
\hline & & & $(0.055)$ & & & $(0.064)$ & & & $(0.058)$ \\
\hline Average cultivable land area & & & 0.000 & & & 0.000 & & & -0.000 \\
\hline & & & $(0.000)$ & & & $(0.000)$ & & & $(0.000)$ \\
\hline $\begin{array}{l}\text { Share of cultivable land area } \\
\text { under irriagation in winter }\end{array}$ & & & 0.036 & & & -0.002 & & & 0.056 \\
\hline & & & $(0.071)$ & & & $(0.081)$ & & & $(0.075)$ \\
\hline $\begin{array}{l}\text { Share of village hhs that } \\
\text { consumed/ purchased fish or } \\
\text { meat in past } 7 \text { days }\end{array}$ & & & $0.157^{*}$ & & & 0.133 & & & $0.159 *$ \\
\hline & & & $(0.084)$ & & & $(0.098)$ & & & $(0.084)$ \\
\hline $\begin{array}{l}\text { Share of villagers passing Grade } \\
5 \text { or higher }\end{array}$ & & & 0.173 & & & 0.274 & & & 0.214 \\
\hline & & & $(0.215)$ & & & $(0.247)$ & & & $(0.225)$ \\
\hline Constant & $0.841^{* * *}$ & $-1.394^{* *}$ & $-1.550^{* * *}$ & $0.805^{* * *}{ }^{\prime}$ & -2.429 & -2.945 & $0.862^{* * *}$ & -0.330 & -0.453 \\
\hline & $(0.031)$ & $(0.561)$ & $(0.565)$ & $(0.042)$ & $(1.890)$ & $(1.953)$ & $(0.025)$ & $(0.456)$ & $(0.457)$ \\
\hline R2 & 0.04 & 0.13 & 0.14 & 0.08 & 0.17 & 0.18 & 0.03 & 0.22 & 0.22 \\
\hline$\rho$ & $0.34^{* * *}$ & $0.27^{* * *}$ & $0.27 * * *$ & $0.31^{* * *}$ & $0.25^{* * *}$ & $0.25^{* * *}$ & $0.54^{* * *}$ & $0.44^{* * *}$ & $0.44 * * *$ \\
\hline No of children & 661 & 661 & 661 & 440 & 440 & 440 & 799 & 799 & 799 \\
\hline Total no of obs. & 2620 & 2620 & 2620 & 1748 & 1748 & 1748 & 3164 & 3164 & 3164 \\
\hline
\end{tabular}

Note: $1{ }^{*} p<.1,{ }^{* *} p<0.05,{ }^{* * *} p<0.01$; robust standard errors in parentheses accounts for clustering at the child level.

2. All regressions control for child random effects. 
Table 4: Impacts of ROSC Project on School Enrolment for Boys and Girls, Bangladesh 2009

Age 6- 10 in 2004

Age 6- 8 in 2004

Age 7- 14 in 2004

Model 1 Model 2 Model 3 Model 4 Model 5 Model 6 Model 7 Model 8 Model 9

\begin{tabular}{|c|c|c|c|c|c|c|c|c|c|}
\hline \multicolumn{10}{|l|}{ A. Boys } \\
\hline \multirow[t]{2}{*}{ G areas* 2006} & 0.078 & 0.083 & 0.083 & $0.154^{*}$ & $0.157^{*}$ & $0.157^{*}$ & 0.008 & 0.011 & 0.011 \\
\hline & $(0.063)$ & $(0.063)$ & $(0.063)$ & $(0.081)$ & $(0.081)$ & $(0.081)$ & $(0.043)$ & $(0.043)$ & $(0.043)$ \\
\hline \multirow[t]{2}{*}{ GA areas* 2006} & 0.068 & 0.071 & 0.070 & 0.083 & 0.086 & 0.086 & 0.015 & 0.017 & 0.017 \\
\hline & $(0.057)$ & $(0.058)$ & $(0.058)$ & $(0.073)$ & $(0.073)$ & $(0.073)$ & $(0.039)$ & $(0.039)$ & $(0.039)$ \\
\hline \multirow[t]{2}{*}{ G areas* 2007} & 0.054 & 0.065 & 0.075 & $0.163^{*}$ & $0.166^{*}$ & $0.172^{*}$ & -0.030 & -0.018 & -0.016 \\
\hline & $(0.076)$ & $(0.075)$ & $(0.076)$ & $(0.090)$ & $(0.088)$ & $(0.088)$ & $(0.059)$ & $(0.058)$ & $(0.059)$ \\
\hline \multirow[t]{2}{*}{ GA areas* 2007} & 0.005 & 0.014 & 0.011 & 0.069 & 0.070 & 0.057 & -0.039 & -0.037 & -0.035 \\
\hline & $(0.071)$ & $(0.072)$ & $(0.073)$ & $(0.085)$ & $(0.084)$ & $(0.086)$ & $(0.053)$ & $(0.054)$ & $(0.054)$ \\
\hline \multirow[t]{2}{*}{ G areas* 2008} & $0.136^{*}$ & $0.148^{*}$ & $0.157^{* *}$ & $0.207^{* *}$ & $0.209 * *$ & $0.215^{* *}$ & 0.043 & 0.055 & 0.057 \\
\hline & $(0.078)$ & $(0.077)$ & $(0.078)$ & $(0.092)$ & $(0.090)$ & $(0.091)$ & $(0.064)$ & $(0.063)$ & $(0.064)$ \\
\hline \multirow[t]{2}{*}{ GA areas* 2008} & 0.004 & 0.012 & 0.009 & 0.026 & 0.027 & 0.014 & -0.030 & -0.029 & -0.026 \\
\hline & $(0.077)$ & $(0.077)$ & $(0.078)$ & $(0.093)$ & $(0.092)$ & $(0.094)$ & $(0.060)$ & (0.059) & $(0.060)$ \\
\hline \multicolumn{10}{|l|}{ Control variables } \\
\hline $\begin{array}{l}\text { Individual \& } \\
\text { households }\end{array}$ & $\mathrm{N}$ & $\mathrm{Y}$ & $Y$ & $\mathrm{~N}$ & Y & Y & $\mathrm{N}$ & $\mathrm{Y}$ & Y \\
\hline Schools & $\mathrm{N}$ & $\mathrm{N}$ & $Y$ & $\mathrm{~N}$ & $\mathrm{~N}$ & $Y$ & $\mathrm{~N}$ & $\mathrm{~N}$ & Y \\
\hline R2 & 0.04 & 0.15 & 0.16 & 0.07 & 0.19 & 0.20 & 0.03 & 0.20 & 0.20 \\
\hline$\rho$ & $0.41 * * *$ & $0.35^{* * *}$ & $0.35 * * *$ & $0.39 * * *$ & $0.33^{* * *}$ & $0.33^{* * *}$ & $0.61 * * *$ & $0.54 * * *$ & $0.54 * * *$ \\
\hline No of children & 334 & 334 & 334 & 219 & 219 & 219 & 424 & 424 & 424 \\
\hline Total no of obs. & 1326 & 1326 & 1326 & 873 & 873 & 873 & 1677 & 1677 & 1677 \\
\hline \multicolumn{10}{|l|}{ B. Girls } \\
\hline \multirow[t]{2}{*}{ G areas* 2006} & $0.160 * * *$ & $0.165^{* * *}$ & $0.167^{* * *}$ & $0.232^{* * *}$ & $0.234^{* * *}$ & $0.237^{* * *}$ & 0.019 & 0.023 & 0.024 \\
\hline & $(0.057)$ & $(0.057)$ & $(0.057)$ & $(0.075)$ & $(0.075)$ & $(0.075)$ & $(0.054)$ & $(0.054)$ & $(0.054)$ \\
\hline \multirow[t]{2}{*}{ GA areas* 2006} & $0.114^{* *}$ & $0.118^{* * *}$ & $0.119 * * *$ & $0.165^{* * *}$ & $0.167^{* * *}$ & $0.169 * * *$ & $0.071^{*}$ & $0.075^{*}$ & $0.075^{*}$ \\
\hline & $(0.046)$ & $(0.046)$ & $(0.046)$ & $(0.061)$ & $(0.061)$ & $(0.061)$ & $(0.042)$ & $(0.043)$ & $(0.043)$ \\
\hline \multirow[t]{2}{*}{ G areas* 2007} & 0.091 & 0.093 & 0.087 & $0.162^{*}$ & $0.160 *$ & $0.154^{*}$ & -0.031 & -0.025 & -0.026 \\
\hline & $(0.068)$ & $(0.068)$ & $(0.068)$ & $(0.085)$ & $(0.085)$ & $(0.085)$ & $(0.063)$ & $(0.062)$ & $(0.062)$ \\
\hline \multirow[t]{2}{*}{ GA areas* 2007} & 0.030 & 0.034 & 0.024 & 0.096 & 0.095 & 0.084 & 0.004 & 0.005 & -0.009 \\
\hline & $(0.057)$ & $(0.057)$ & $(0.058)$ & $(0.072)$ & $(0.072)$ & $(0.073)$ & $(0.053)$ & $(0.052)$ & $(0.053)$ \\
\hline \multirow[t]{2}{*}{ G areas* 2008} & 0.095 & 0.097 & 0.091 & 0.143 & 0.140 & 0.135 & -0.007 & -0.001 & -0.002 \\
\hline & $(0.077)$ & $(0.077)$ & $(0.077)$ & $(0.095)$ & $(0.095)$ & $(0.095)$ & $(0.070)$ & $(0.069)$ & $(0.069)$ \\
\hline \multirow[t]{2}{*}{ GA areas* 2008} & 0.012 & 0.015 & 0.005 & 0.073 & 0.072 & 0.061 & -0.020 & -0.019 & -0.032 \\
\hline & $(0.067)$ & $(0.067)$ & $(0.068)$ & $(0.080)$ & $(0.080)$ & $(0.080)$ & $(0.061)$ & $(0.060)$ & $(0.060)$ \\
\hline \multicolumn{10}{|l|}{ Control variables } \\
\hline $\begin{array}{l}\text { Individual \& } \\
\text { households }\end{array}$ & $\mathrm{N}$ & $\mathrm{Y}$ & $Y$ & $\mathrm{~N}$ & $\mathrm{Y}$ & $\mathrm{Y}$ & $\mathrm{N}$ & $Y$ & $\mathrm{Y}$ \\
\hline Schools & $\mathrm{N}$ & $\mathrm{N}$ & $Y$ & $\mathrm{~N}$ & $\mathrm{~N}$ & $\mathrm{Y}$ & $\mathrm{N}$ & $\mathrm{N}$ & $Y$ \\
\hline R2 & 0.06 & 0.10 & 0.11 & 0.12 & 0.16 & 0.17 & 0.04 & 0.22 & 0.23 \\
\hline$\rho$ & $0.17^{* * *}$ & $0.14^{* * *}$ & $0.14^{* * *}$ & $0.15^{* * *}$ & $0.11^{* * *}$ & $0.11^{* * *}$ & $0.41 * * *$ & $0.28 * * *$ & $0.28 * * *$ \\
\hline No of children & 327 & 327 & 327 & 221 & 221 & 221 & 375 & 375 & 375 \\
\hline Total no of obs. & 1294 & 1294 & 1294 & 875 & 875 & 875 & 1487 & 1487 & 1487 \\
\hline
\end{tabular}

Note: $1 .{ }^{*} p<.1, * * p<0.05, * * * p<0.01$; robust standard errors in parentheses accounts for clustering at the child lev 2. All regressions control for child random effects.

3. The control variables for the regressions are the same as those in Table 3. 
Table 5: Impacts of ROSC Schools on Test Scores Compared to Non-ROSC Schools, Bangladesh 2009

\begin{tabular}{|c|c|c|c|c|c|c|c|c|c|}
\hline & \multicolumn{3}{|c|}{ Bangla Scores } & \multicolumn{3}{|c|}{ Math Scores } & \multicolumn{3}{|c|}{ Combined Scores } \\
\hline & Model 1 & Model 2 & Model 3 & Model 4 & Model 5 & Model 6 & Model 7 & Model 8 & Model 9 \\
\hline \multirow[t]{2}{*}{ G schools* 2009} & 0.014 & 0.014 & 0.014 & 0.013 & 0.012 & 0.012 & -0.003 & -0.003 & -0.003 \\
\hline & $(0.076)$ & $(0.076)$ & $(0.076)$ & $(0.085)$ & $(0.085)$ & $(0.085)$ & $(0.071)$ & $(0.071)$ & $(0.071)$ \\
\hline \multirow[t]{2}{*}{ GA schools* 2009} & 0.076 & 0.076 & 0.076 & 0.063 & 0.062 & 0.061 & 0.060 & 0.060 & 0.060 \\
\hline & $(0.077)$ & $(0.078)$ & $(0.078)$ & $(0.087)$ & $(0.087)$ & $(0.088)$ & $(0.073)$ & $(0.073)$ & $(0.073)$ \\
\hline \multirow[t]{2}{*}{ G schools } & -0.082 & -0.078 & 0.027 & -0.020 & -0.026 & 0.035 & -0.066 & -0.063 & 0.038 \\
\hline & $(0.070)$ & $(0.071)$ & $(0.075)$ & $(0.067)$ & $(0.069)$ & $(0.075)$ & $(0.065)$ & $(0.067)$ & $(0.071)$ \\
\hline \multirow[t]{2}{*}{ GA schools } & $-0.612^{* * *}$ & $-0.605 * * *$ & $-0.459 * * *$ & $-0.313^{* * *}$ & $-0.313^{* * *}$ & $-0.189 * *$ & $-0.565 * * *$ & $-0.556 * * *$ & $-0.393 * * *$ \\
\hline & $(0.071)$ & $(0.074)$ & $(0.081)$ & $(0.070)$ & $(0.073)$ & $(0.081)$ & $(0.067)$ & $(0.071)$ & $(0.078)$ \\
\hline \multirow[t]{2}{*}{ Year 2009} & $0.478^{* * *}$ & $0.478 * * *$ & $0.478 * * *$ & $0.423^{* * *}$ & $0.423^{* * *}$ & $0.423^{* * *}$ & $0.526 * * *$ & $0.526 * * *$ & $0.526 * * *$ \\
\hline & $(0.065)$ & $(0.066)$ & $(0.066)$ & $(0.076)$ & $(0.076)$ & $(0.076)$ & $(0.061)$ & $(0.061)$ & $(0.061)$ \\
\hline \multirow[t]{2}{*}{ Age } & & 0.003 & 0.005 & & 0.004 & 0.005 & & 0.004 & 0.006 \\
\hline & & $(0.004)$ & $(0.004)$ & & $(0.004)$ & $(0.005)$ & & $(0.004)$ & $(0.005)$ \\
\hline \multirow[t]{2}{*}{ Female } & & $0.095^{* * *}$ & $0.096 * * *$ & & -0.025 & -0.024 & & $0.055^{*}$ & $0.056^{*}$ \\
\hline & & $(0.033)$ & $(0.032)$ & & $(0.032)$ & $(0.031)$ & & $(0.032)$ & $(0.031)$ \\
\hline \multirow[t]{2}{*}{ Household asset index } & & $0.024^{* *}$ & $0.026 * *$ & & 0.016 & $0.021^{* *}$ & & $0.025^{* *}$ & $0.029 * * *$ \\
\hline & & $(0.011)$ & $(0.010)$ & & $(0.010)$ & $(0.010)$ & & $(0.010)$ & $(0.010)$ \\
\hline \multirow[t]{2}{*}{ Literate parent(s) } & & $0.063 *$ & 0.054 & & $0.058^{*}$ & $0.055^{*}$ & & $0.077^{* *}$ & $0.070^{* *}$ \\
\hline & & $(0.034)$ & $(0.034)$ & & $(0.034)$ & $(0.033)$ & & $(0.033)$ & $(0.033)$ \\
\hline \multirow[t]{2}{*}{ Female head } & & $-0.101^{*}$ & -0.081 & & -0.058 & -0.042 & & $-0.092^{*}$ & -0.070 \\
\hline & & $(0.053)$ & $(0.052)$ & & $(0.053)$ & $(0.054)$ & & $(0.052)$ & $(0.051)$ \\
\hline \multirow[t]{2}{*}{ Household size } & & -0.003 & 0.002 & & -0.006 & -0.002 & & -0.004 & 0.000 \\
\hline & & $(0.010)$ & $(0.010)$ & & $(0.009)$ & $(0.009)$ & & $(0.010)$ & $(0.009)$ \\
\hline \multirow[t]{2}{*}{ Time to school } & & $-0.004 * *$ & $-0.004 *$ & & -0.004 & -0.003 & & $-0.005^{* *}$ & $-0.004 *$ \\
\hline & & $(0.002)$ & $(0.002)$ & & $(0.002)$ & $(0.002)$ & & $(0.002)$ & $(0.002)$ \\
\hline \multicolumn{2}{|c|}{ English homework most of the week } & & 0.068 & & & $0.136^{* *}$ & & & 0.100 \\
\hline & & & $(0.064)$ & & & $(0.065)$ & & & $(0.064)$ \\
\hline \multicolumn{2}{|c|}{ Math homework most of the week } & & -0.021 & & & -0.079 & & & -0.038 \\
\hline & & & $(0.066)$ & & & $(0.067)$ & & & $(0.066)$ \\
\hline \multicolumn{2}{|c|}{ No of days school open last 2 weeks } & & -0.006 & & & 0.006 & & & -0.001 \\
\hline & & & $(0.008)$ & & & $(0.009)$ & & & $(0.008)$ \\
\hline \multirow[t]{2}{*}{ Condition of blackboard } & & & $0.227^{* * *}$ & & & $0.147^{* * *}$ & & & $0.227^{* * *}$ \\
\hline & & & $(0.032)$ & & & $(0.032)$ & & & $(0.031)$ \\
\hline School has toilet & & & 0.002 & & & $-0.063^{*}$ & & & -0.017 \\
\hline & & & $(0.038)$ & & & $(0.035)$ & & & $(0.036)$ \\
\hline School has alphabetic chart & & & -0.058 & & & $-0.167^{* * *}$ & & & $-0.116 * * *$ \\
\hline & & & $(0.045)$ & & & $(0.042)$ & & & $(0.043)$ \\
\hline School has number chart & & & $0.159 * * *$ & & & $0.202^{* * *}$ & & & $0.195^{* * *}$ \\
\hline & & & $(0.050)$ & & & $(0.047)$ & & & $(0.047)$ \\
\hline School has electricity & & & -0.002 & & & -0.033 & & & -0.016 \\
\hline & & & $(0.048)$ & & & $(0.046)$ & & & $(0.045)$ \\
\hline School has water & & & $0.087^{* *}$ & & & $0.184^{* * *}$ & & & $0.145^{* * *}$ \\
\hline & & & $(0.040)$ & & & $(0.039)$ & & & $(0.038)$ \\
\hline Constant & $0.432 * * *$ & $0.365^{* * *}$ & $-0.473 * * *$ & $0.282 * * *$ & $0.284^{* * *}$ & $-0.429 * *$ & $0.425^{* * *}$ & $0.370^{* * *}$ & $-0.561 * * *$ \\
\hline & $(0.061)$ & $(0.096)$ & $(0.176)$ & $(0.059)$ & $(0.096)$ & $(0.186)$ & $(0.056)$ & $(0.095)$ & $(0.176)$ \\
\hline $\mathrm{R} 2$ & 0.14 & 0.15 & 0.17 & 0.08 & 0.09 & 0.11 & 0.16 & 0.16 & 0.19 \\
\hline$\rho$ & $0.22 * * *$ & $0.22 * * *$ & $0.20 * * *$ & $0.16^{* * *}$ & $0.16^{* * *}$ & $0.14 * * *$ & $0.25^{* * *}$ & $0.24 * * *$ & $0.22 * * *$ \\
\hline No of children & 1832 & 1832 & 1832 & 1832 & 1832 & 1832 & 1832 & 1832 & 1832 \\
\hline Total no of obs. & 3659 & 3659 & 3659 & 3624 & 3624 & 3624 & 3661 & 3661 & 3661 \\
\hline
\end{tabular}

Note: $1 .{ }^{*} \mathrm{p}<.1,{ }^{*} \mathrm{p}<0.05, * * * \mathrm{p}<0.01$; robust standard errors in parentheses accounts for clustering at the child level.

2. All regressions control for child random effects. 
Table 6 :Impacts of ROSC Schools on Test Scores for Boys and Girls, Bangladesh 2009

\section{Bangla Scores}

Math Scores

Combined Scores

Model 1 Model 2 Model 3 Model 4 Model 5 Model 6 Model 7 Model 8 Model 9

\begin{tabular}{|c|c|c|c|c|c|c|c|c|c|}
\hline \multirow{2}{*}{\multicolumn{10}{|c|}{ A. Boys }} \\
\hline & & & & & & & & & \\
\hline \multirow[t]{2}{*}{ G schools* 2009} & -0.003 & -0.003 & -0.003 & -0.113 & -0.113 & -0.114 & -0.071 & -0.071 & -0.071 \\
\hline & $(0.106)$ & $(0.106)$ & $(0.106)$ & $(0.122)$ & $(0.122)$ & $(0.123)$ & $(0.098)$ & $(0.098)$ & $(0.098)$ \\
\hline \multirow[t]{2}{*}{ GA schools* 2009} & 0.135 & 0.135 & 0.136 & -0.088 & -0.088 & -0.091 & 0.036 & 0.036 & 0.036 \\
\hline & $(0.108)$ & $(0.108)$ & $(0.108)$ & $(0.127)$ & $(0.127)$ & $(0.127)$ & $(0.101)$ & $(0.101)$ & $(0.101)$ \\
\hline \multicolumn{10}{|l|}{ Control variables } \\
\hline $\begin{array}{l}\text { Individual \& } \\
\text { households }\end{array}$ & $\mathrm{N}$ & $\mathrm{Y}$ & $\mathrm{Y}$ & $\mathrm{N}$ & $Y$ & Y & $\mathrm{N}$ & Y & Y \\
\hline Schools & $\mathrm{N}$ & $\mathrm{N}$ & $Y$ & $\mathrm{~N}$ & $\mathrm{~N}$ & $\mathrm{Y}$ & $\mathrm{N}$ & $\mathrm{N}$ & $Y$ \\
\hline R2 & 0.17 & 0.19 & 0.21 & 0.10 & 0.10 & 0.13 & 0.19 & 0.20 & 0.23 \\
\hline$\rho$ & $0.21 * * *$ & $0.20 * * *$ & $0.19^{* * *}$ & $0.13^{* * *}$ & $0.13^{* * *}$ & $0.10^{* * *}$ & $0.23 * * *$ & $0.22^{* * *}$ & $0.19 * * *$ \\
\hline No of children & 965 & 965 & 965 & 965 & 965 & 965 & 965 & 965 & 965 \\
\hline Total no of obs. & 1926 & 1926 & 1926 & 1910 & 1910 & 1910 & 1928 & 1928 & 1928 \\
\hline \multicolumn{10}{|l|}{ B. Girls } \\
\hline \multirow[t]{2}{*}{ G schools*2009 } & 0.019 & 0.019 & 0.019 & 0.114 & 0.114 & 0.114 & 0.046 & 0.046 & 0.046 \\
\hline & $(0.108)$ & $(0.108)$ & $(0.108)$ & $(0.119)$ & $(0.119)$ & $(0.119)$ & $(0.101)$ & $(0.101)$ & $(0.101)$ \\
\hline \multirow[t]{2}{*}{ GA schools* 2009} & 0.006 & 0.006 & 0.006 & 0.194 & 0.194 & 0.193 & 0.067 & 0.067 & 0.067 \\
\hline & $(0.111)$ & $(0.111)$ & $(0.111)$ & $(0.120)$ & $(0.120)$ & $(0.120)$ & $(0.104)$ & $(0.104)$ & $(0.105)$ \\
\hline \multicolumn{10}{|l|}{ Control variables } \\
\hline $\begin{array}{l}\text { Individual \& } \\
\text { households }\end{array}$ & $\mathrm{N}$ & $Y$ & $Y$ & $\mathrm{~N}$ & $Y$ & Y & $\mathrm{N}$ & Y & $Y$ \\
\hline Schools & $\mathrm{N}$ & $\mathrm{N}$ & Y & $\mathrm{N}$ & $\mathrm{N}$ & Y & $\mathrm{N}$ & $\mathrm{N}$ & $\mathrm{Y}$ \\
\hline R2 & 0.12 & 0.12 & 0.16 & 0.07 & 0.07 & 0.10 & 0.12 & 0.13 & 0.17 \\
\hline$\rho$ & $0.23 * * *$ & $0.23 * * *$ & $0.20 * * *$ & $0.19 * * *$ & $0.19 * * *$ & $0.18^{* * *}$ & $0.26 * * *$ & $0.26 * * *$ & $0.23 * * *$ \\
\hline No of children & 867 & 867 & 867 & 867 & 867 & 867 & 867 & 867 & 867 \\
\hline Total no of obs. & 1733 & 1733 & 1733 & 1714 & 1714 & 1714 & 1733 & 1733 & 1733 \\
\hline
\end{tabular}

Note: $1 .{ }^{*} \mathrm{p}<.1,{ }^{* *} \mathrm{p}<0.05,{ }^{* * *} \mathrm{p}<0.01$; robust standard errors in parentheses accounts for clustering at the child lev 2. All regressions control for child random effects.

3. The control variables for the regressions are the same as those in Table 5. 
Table 7: Robustness Checks on Impacts of ROSC Schools on Test Scores, Bangladesh 2009

\begin{tabular}{|c|c|c|c|c|c|c|c|c|c|}
\hline & \multicolumn{3}{|c|}{ Bangla Scores } & \multicolumn{3}{|c|}{ Math Scores } & \multicolumn{3}{|c|}{ Combined Scores } \\
\hline & Model 1 & Model 2 & Model 3 & Model 4 & Model 5 & Model 6 & Model 7 & Model 8 & Model 9 \\
\hline \multirow[t]{2}{*}{ Quartile 1* G schools*2009 } & -0.083 & -0.072 & -0.074 & -0.041 & -0.038 & -0.036 & $-0.165^{*}$ & -0.154 & $-0.158^{*}$ \\
\hline & $(0.095)$ & $(0.095)$ & $(0.096)$ & $(0.108)$ & $(0.108)$ & $(0.108)$ & $(0.094)$ & $(0.095)$ & $(0.094)$ \\
\hline \multirow[t]{2}{*}{ Quartile 2* G schools* 2009} & -0.004 & 0.010 & 0.004 & 0.009 & 0.012 & -0.005 & 0.023 & 0.029 & 0.010 \\
\hline & $(0.093)$ & $(0.094)$ & $(0.094)$ & $(0.094)$ & $(0.094)$ & $(0.095)$ & $(0.083)$ & $(0.083)$ & $(0.083)$ \\
\hline \multirow[t]{2}{*}{ Quartile 3* G schools* 2009} & 0.029 & 0.026 & 0.022 & 0.041 & 0.038 & 0.046 & 0.025 & 0.021 & 0.023 \\
\hline & $(0.083)$ & $(0.083)$ & $(0.083)$ & $(0.090)$ & $(0.090)$ & $(0.090)$ & $(0.076)$ & $(0.076)$ & $(0.076)$ \\
\hline \multirow[t]{2}{*}{ Quartile 4* G schools* 2009} & 0.075 & 0.062 & 0.073 & -0.003 & -0.007 & 0.008 & 0.025 & 0.019 & 0.037 \\
\hline & $(0.083)$ & $(0.083)$ & $(0.084)$ & $(0.111)$ & $(0.110)$ & $(0.110)$ & $(0.081)$ & (0.081) & $(0.081)$ \\
\hline \multirow[t]{2}{*}{ Quartile 1* GA schools* 2009} & -0.041 & -0.041 & -0.028 & -0.043 & -0.040 & -0.013 & -0.075 & -0.075 & -0.056 \\
\hline & $(0.087)$ & $(0.087)$ & $(0.087)$ & $(0.100)$ & $(0.101)$ & $(0.101)$ & $(0.085)$ & $(0.085)$ & $(0.085)$ \\
\hline \multirow[t]{2}{*}{ Quartile 2* GA schools* 2009} & 0.034 & 0.034 & 0.063 & 0.049 & 0.042 & 0.055 & 0.010 & 0.006 & 0.012 \\
\hline & $(0.096)$ & $(0.096)$ & $(0.095)$ & $(0.103)$ & $(0.103)$ & $(0.103)$ & $(0.087)$ & $(0.087)$ & $(0.085)$ \\
\hline \multirow[t]{2}{*}{ Quartile 3* GA schools* 2009} & $0.314^{* * *}$ & $0.314^{* * *}$ & $0.280 * * *$ & 0.068 & 0.066 & 0.042 & $0.279 * * *$ & $0.272^{* * *}$ & $0.243^{* * *}$ \\
\hline & $(0.093)$ & $(0.093)$ & $(0.093)$ & $(0.100)$ & $(0.100)$ & $(0.099)$ & $(0.092)$ & $(0.092)$ & $(0.091)$ \\
\hline \multirow[t]{2}{*}{ Quartile 4* GA schools* 2009} & 0.127 & 0.127 & 0.100 & $0.354^{* * *}$ & $0.357^{* * *}$ & $0.306^{* * *}$ & $0.184^{* *}$ & $0.198^{* *}$ & $0.179 *$ \\
\hline & $(0.108)$ & $(0.107)$ & $(0.106)$ & $(0.105)$ & $(0.105)$ & $(0.108)$ & $(0.091)$ & $(0.091)$ & $(0.091)$ \\
\hline \multicolumn{10}{|l|}{ Control variables } \\
\hline Individual \& households & $\mathrm{N}$ & $\mathrm{Y}$ & $\mathrm{Y}$ & $\mathrm{N}$ & $\mathrm{Y}$ & Y & $\mathrm{N}$ & $\mathrm{Y}$ & $\mathrm{Y}$ \\
\hline Schools & $\mathrm{N}$ & $\mathrm{N}$ & $\mathrm{Y}$ & $\mathrm{N}$ & $\mathrm{N}$ & Y & $\mathrm{N}$ & $\mathrm{N}$ & $Y$ \\
\hline R2 & 0.16 & 0.16 & 0.18 & 0.09 & 0.09 & 0.11 & 0.17 & 0.18 & 0.20 \\
\hline$\rho$ & $0.09 * * *$ & $0.09 * * *$ & $0.08 * * *$ & $0.07 * * *$ & $0.07 * * *$ & $0.06 * * *$ & $0.10 * * *$ & $0.09 * * *$ & $0.07 * * *$ \\
\hline No of children & 1832 & 1832 & 1832 & 1832 & 1832 & 1832 & 1832 & 1832 & 1832 \\
\hline Total no of obs. & 3659 & 3659 & 3659 & 3624 & 3624 & 3624 & 3661 & 3661 & 3661 \\
\hline
\end{tabular}

Note: $1 .{ }^{*} p<.1,{ }^{*} p<0.05,{ }^{* * *} p<0.01$; robust standard errors in parentheses accounts for clustering at the child level.

2. All regressions control for child random effects.

3. The control variables for the regressions are the same as those in Table 5. 
Table 8: Impacts of Other School Types on Test Scores, Bangladesh 2009

\begin{tabular}{|c|c|c|c|c|c|c|c|c|c|}
\hline & \multicolumn{3}{|c|}{ Bangla Scores } & \multicolumn{3}{|c|}{ Math Scores } & \multicolumn{3}{|c|}{ Combined Scores } \\
\hline & Model 1 & Model 2 & Model 3 & Model 4 & Model 5 & Model 6 & Model 7 & Model 8 & Model 9 \\
\hline \multirow[t]{2}{*}{ G schools* 2009} & 0.014 & 0.014 & 0.014 & 0.013 & 0.012 & 0.012 & -0.003 & -0.003 & -0.003 \\
\hline & $(0.076)$ & $(0.076)$ & $(0.076)$ & $(0.085)$ & $(0.085)$ & $(0.085)$ & $(0.071)$ & $(0.071)$ & $(0.071)$ \\
\hline \multirow[t]{2}{*}{ GA schools* 2009} & 0.076 & 0.076 & 0.076 & 0.063 & 0.063 & 0.061 & 0.060 & 0.060 & 0.060 \\
\hline & $(0.077)$ & $(0.078)$ & $(0.078)$ & $(0.087)$ & $(0.087)$ & $(0.088)$ & $(0.073)$ & $(0.073)$ & $(0.073)$ \\
\hline \multirow[t]{2}{*}{$\begin{array}{l}\text { Non-ROSC } \\
\text { schools in G } \\
\text { areas* } 2009\end{array}$} & $0.529 * * *$ & $0.529 * * *$ & $0.529 * * *$ & $0.341^{* * *}$ & $0.340^{* * *}$ & $0.340^{* * *}$ & $0.516 * * *$ & $0.516^{* * *}$ & $0.516^{* * *}$ \\
\hline & $(0.096)$ & $(0.096)$ & $(0.096)$ & $(0.113)$ & $(0.113)$ & $(0.113)$ & (0.096) & $(0.096)$ & $(0.096)$ \\
\hline \multirow[t]{2}{*}{$\begin{array}{l}\text { Non-ROSC } \\
\text { schools in GA } \\
\text { areas* } 2009\end{array}$} & $0.228^{* *}$ & $0.228^{* *}$ & $0.228^{* *}$ & 0.072 & 0.072 & 0.072 & $0.166^{*}$ & $0.166^{*}$ & $0.166^{*}$ \\
\hline & $(0.092)$ & $(0.092)$ & $(0.092)$ & (0.109) & (0.109) & (0.110) & $(0.088)$ & $(0.088)$ & (0.088) \\
\hline \multicolumn{10}{|l|}{ Control variables } \\
\hline $\begin{array}{l}\text { Individual \& } \\
\text { households }\end{array}$ & $\mathrm{N}$ & Y & Y & $\mathrm{N}$ & Y & Y & $\mathrm{N}$ & Y & Y \\
\hline Schools & $\mathrm{N}$ & $\mathrm{N}$ & Y & $\mathrm{N}$ & $\mathrm{N}$ & Y & $\mathrm{N}$ & $\mathrm{N}$ & Y \\
\hline $\mathrm{R} 2$ & 0.16 & 0.17 & 0.19 & 0.09 & 0.09 & 0.11 & 0.17 & 0.18 & 0.20 \\
\hline$\rho$ & $0.23^{* * *}$ & $0.22 * * *$ & $0.21^{* * *}$ & $0.14^{* * *}$ & $0.14^{* * *}$ & $0.12^{* * *}$ & $0.25^{* * *}$ & $0.24 * * *$ & $0.22^{* * *}$ \\
\hline No of children & 2306 & 2306 & 2306 & 2306 & 2306 & 2306 & 2306 & 2306 & 2306 \\
\hline Total no of obs. & 4607 & 4607 & 4607 & 4563 & 4563 & 4563 & 4609 & 4609 & 4609 \\
\hline
\end{tabular}

Note: $1 .{ }^{*} p<.1,{ }^{* *} p<0.05,{ }^{* * *} p<0.01$; robust standard errors in parentheses accounts for clustering at the child level.

2. All regressions control for child random effects.

3. The control variables for the regressions are the same as those in Table 5. 


\begin{tabular}{|c|c|c|c|}
\hline \multicolumn{3}{|c|}{ Appendix 1: Comparison of ROSC, BRAC, and GP Schools } & \multirow[b]{2}{*}{ GPS } \\
\hline & ROSC & BRAC & \\
\hline \multirow{4}{*}{$\begin{array}{l}\text { Organization/ } \\
\text { Management }\end{array}$} & Low teacher absenteism & Low teacher absenteism & High teacher absenteism \\
\hline & Multigrade & Multigrade & Single grade \\
\hline & No school fees & No school fees & School fees \\
\hline & Strong community involvement & Strong community involvement & (Varies) \\
\hline \multirow{3}{*}{ Teacher } & One teacher & One teacher & $\begin{array}{l}\text { More than one teachers (3- } 5 \text { in } \\
\text { rural schools) }\end{array}$ \\
\hline & $\begin{array}{l}\text { Teacher follows students to end of } \\
\text { cycle }\end{array}$ & $\begin{array}{l}\text { Teacher follows students to end of } \\
\text { cycle }\end{array}$ & Different teacher for each grade \\
\hline & $\begin{array}{l}\text { Most teachers recruited from local } \\
\text { community }\end{array}$ & $\begin{array}{l}\text { Most teachers recruited from local } \\
\text { community }\end{array}$ & (Varies) \\
\hline \multirow[b]{2}{*}{ Infrastructure } & One classroom school & One classroom school & Multi-classroom school \\
\hline & $\begin{array}{l}\text { Medium/ Small class size (35 or } \\
\text { less) }\end{array}$ & Small class size ( 30 or less) & Large class size (33 or more) \\
\hline \multirow{3}{*}{ Curriculum } & Own textbooks & Own texbooks (Grade 1-3) & Own textbooks \\
\hline & No life skill in curriculum & Life skills included in curriculum & No life skill in curriculum \\
\hline & Classroom is child-centered & Classroom is child-centered & Classroom is NOT child-centered \\
\hline
\end{tabular}

